\title{
The evolution of the metazoan Toll receptor family and its expression during protostome development
}

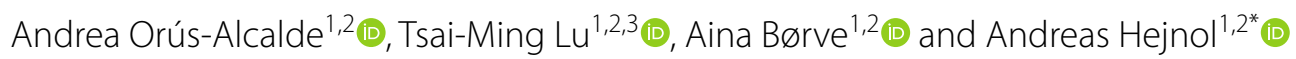

\begin{abstract}
Background: Toll-like receptors (TLRs) play a crucial role in immunity and development. They contain leucine-rich repeat domains, one transmembrane domain, and one Toll/IL-1 receptor domain. TLRs have been classified into V-type/scc and P-type/mcc TLRs, based on differences in the leucine-rich repeat domain region. Although TLRs are widespread in animals, detailed phylogenetic studies of this gene family are lacking. Here we aim to uncover TLR evolution by conducting a survey and a phylogenetic analysis in species across Bilateria. To discriminate between their role in development and immunity we furthermore analyzed stage-specific transcriptomes of the ecdysozoans Priapulus caudatus and Hypsibius exemplaris, and the spiralians Crassostrea gigas and Terebratalia transversa.

Results: We detected a low number of TLRs in ecdysozoan species, and multiple independent radiations within the Spiralia. V-type/scc and P-type/mcc type-receptors are present in cnidarians, protostomes and deuterostomes, and therefore they emerged early in TLR evolution, followed by a loss in xenacoelomorphs. Our phylogenetic analysis shows that TLRs cluster into three major clades: clade $\alpha$ is present in cnidarians, ecdysozoans, and spiralians; clade $\beta$ in deuterostomes, ecdysozoans, and spiralians; and clade $\gamma$ is only found in spiralians. Our stage-specific transcriptome and in situ hybridization analyses show that TLRs are expressed during development in all species analyzed, which indicates a broad role of TLRs during animal development.

Conclusions: Our findings suggest that a clade a TLR gene (TLR-Ca) and a clade $\beta / Y T L R$ gene (TLR-C $\beta / \gamma$ ) were already present in the cnidarian-bilaterian common ancestor. However, although TLR-Ca was conserved in cnidarians, TLR$C \beta / \gamma$ was lost during the early evolution of these taxa. Moreover, TLR-C $C / Y$ duplicated to generate TLR-C $\beta$ and TLR-CY in the lineage to the last common protostome-deuterostome ancestor. $T L R-C a, T L R-C \beta$ and $T L R-C \gamma$ further expanded generating the three major TLR clades. While all three clades radiated in several spiralian lineages, specific TLRs clades have been presumably lost in other lineages. Furthermore, the expression of the majority of these genes during protostome ontogeny suggests a likely role in development.
\end{abstract}

Keywords: Toll receptor, Toll-like receptor, Innate immunity, Development, Metazoan evolution, Gene duplication

*Correspondence: andreas.hejnol@uib.no

${ }^{2}$ Department of Biological Sciences, University of Bergen, Bergen, Norway

Full list of author information is available at the end of the article

\section{Background}

Toll-like receptors (TLRs) are involved in immunity and development in metazoans [1-7]. The first described TLR was the Drosophila gene Toll, which plays a role during early embryonic development $[8,9]$ and in immunity [10]. The human toll receptor TLR4 was the first TLR discovered in mammals [11]. Since then, TLRs have been found in most planulozoans (Cnidaria + Bilateria) 
[12-14]. Both in vertebrates and invertebrates, these receptors recognize pathogens and activate the Toll pathway, which induces the expression of downstream immune genes [15-17]. In Drosophila, TLRs are mainly activated by gram-positive bacteria, fungi, and viruses, promoting the synthesis of antimicrobial peptides (AMPs) [4, 10, 17-21]. In vertebrates, TLRs are involved in innate immunity and in the activation and regulation of adaptive immunity [11, 22-26]. TLRs are also involved in the immunity of other animals such as cnidarians [27], mollusks [28-31], annelids [32, 33], crustaceans [34] and echinoderms [35]. The developmental roles of TLRs in Drosophila [reviewed in 2] comprise the establishment of the dorso-ventral axis [8, 9], segmentation [36], axis elongation [37], muscle and neuronal development [38, 39], wing formation [40, 41] and heart formation [42]. TLRs also play a role in cnidarian development [27]. Moreover, in ecdysozoans, TLRs are likely involved in onychophoran axis elongation [43]. In spiralians, TLRs are expressed during the development of mollusks [31] and annelids [32], but no further analyses have been conducted. TLRs are also involved in nervous system development in mice [44-47], although the ligands that activate them during this process remain unknown [2].

TLRs are proteins characterized by an extracellular region containing one or more leucine-rich repeat (LRR) domains, one type-I transmembrane domain and one intracellular Toll/IL-1 receptor (TIR) domain (Fig. 1) [48, 49]. The extracellular LRR domains are the regions that recognize the ligand $[50,51]$. Each LRR domain is constituted by 22-26 amino acids, in which multiple leucine residues are present [48]. Some LRR domains contain cysteine residues in the $\mathrm{N}$-terminal (LRRNT) or the C-terminal (LRRCT) part of the LRR domain $[6,49,52]$. However, LRR domains are also found in a large number of other proteins [53], for example in the immune NOD receptors [54] and in proteins involved in developmental processes (e.g. Slit, Capricious, Tartan) [55, 56]. The TIR domain is involved in signal transduction [49] and is also present in other proteins, e.g. in immune proteins in plants $[57,58]$, in members of the interleukin-I receptor family (IL-1) $[49,59]$ and in adaptors of the Toll pathway (e.g. MyD88) [60-62]. Although the TIR domain is the most characteristic domain of the TLRs, at least one LRR domain must be present to categorize a receptor as TLR (Fig. 1) [13].

Based on the structure of the LRR domains, TLRs have been previously classified as vertebrate-type or single cysteine cluster (V-type/scc), and protostome-type or multiple cysteine cluster (P-type/mcc) (Fig. 1) [7, 13, 63, 64]. V-type/scc TLRs are characterized by having only one LRRCT domain, which is located next to the cellular membrane. P-type/mcc TLRs contain at least two

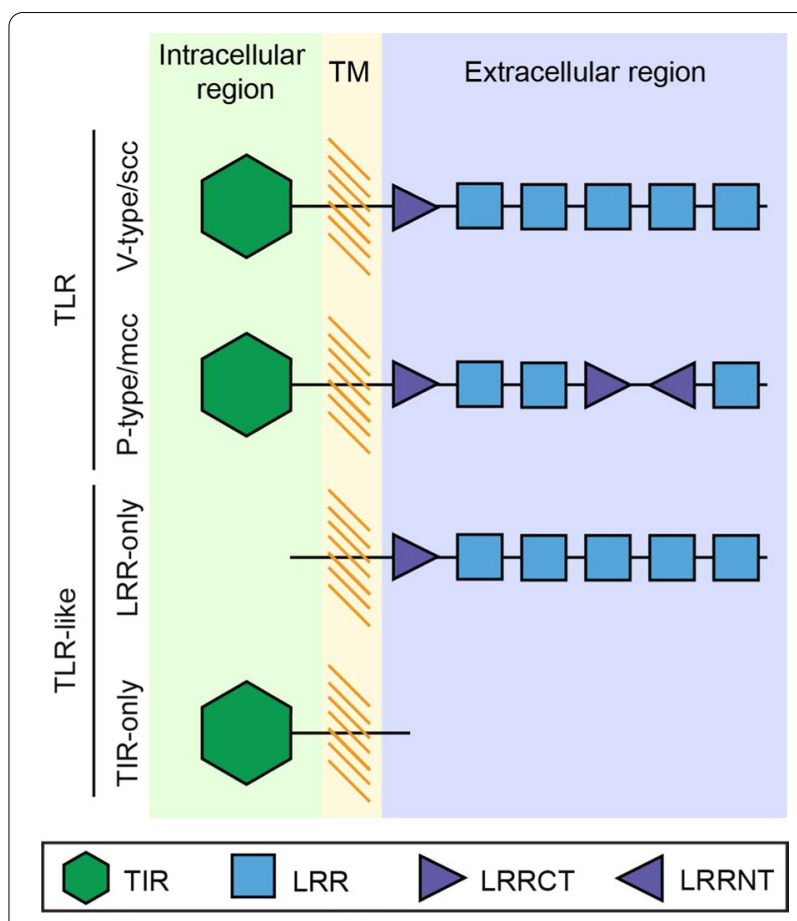

Fig. 1 Structure of TLR and TLR-like receptors. TLRs are constituted by a series of extracellular leucine-rich repeat (LRR) domains, a transmembrane region (TM) and an intracellular Toll/IL-1 receptor (TIR) domain. TLRs are often classified into V-type/scc or P-type/ mcc according to the structure of their extracellular region. V-type/ scc TLRs have only one LRRCT located next to the TIR domain, while P-type/mcc TLRs have more than one LRRCT and, sometimes, an LRRNT domain. Proteins that lack either the LRR domains or the TIR domain are not considered as TLR receptors. These TLR-like proteins are classified in LRR-only or TIR-only. [Adapted from 7, 13]

LRRCT domains and, commonly, an LRRNT [7, 13]. Traditionally, it has been assumed that all deuterostome TLRs belong to the V-type/scc [64], and because Drosophila melanogaster TLRs (except for Toll9) and the Caenorhabditis elegans TLR belong to the P-type/mcc, they have been suggested to be protostome specific [64]. However, P-type TLR are also present in invertebrate deuterostomes and V-type TLRs in protostomes $[13,14,65,66]$. Therefore, in agreement with Davidson et al. [65]; and Halanych and Kocot [66], we affirm that the V- P-type nomenclature is problematic and should be avoided in favor of the $\mathrm{mcc} / \mathrm{scc}$ nomenclature.

Several authors consider that TLRs originated in the branch to the Planulozoa by the fusion of a gene with a TIR domain (TIR-only) and a gene containing only LRR domains (LRR-only) [7, 14, 67]. However, this hypothesis is challenged by the presence of TLRs in choanoflagellates, the sister group to metazoans, which suggests that the origin of TLR could predate metazoans [68]. LRR-only and TIR-only are TLR-like proteins (Fig. 1) involved in immunity [7, 12-14, 69-74]-e.g. in Hydra, 
association of LRR-only and TIR-only proteins activates the Toll pathway $[75,76]$.

The TLR complement has been previously surveyed in vertebrates [11, 52, 77-79] and in a few invertebrates, especially in arthropods $[8,14,18,80,81]$. Humans have 10 TLRs $[11,52], D$. melanogaster has 9 [8, 18] and the nematode C. elegans has only one [82]. Recent genome and transcriptome sequencing of more organisms has revealed that TLRs are widespread across the metazoan tree (summary in Fig. 2). Outside bilaterians, TLRs are present in anthozoan cnidarians (e.g. Nematostella [27], Acropora [72], Orbicella [83]), but not in hydrozoans (e.g. Hydra [75], Clytia [84]). Furthermore, TLRs have not been found in ctenophores $[85,86]$, placozoans [73] and poriferans $[69,74]$. Within bilaterians, previous studies have shown that the number of TLRs in spiralians is highly variable between species [65, 66, 87-90], suggesting that TLR genes underwent several independent radiations [13, 65, 89, 91]. However, the surveyed platyhelminth and rotifer species lack TLRs [70, 71, 92]. In ecdysozoans, besides arthropods and nematodes, TLRs are also present in onychophorans, tardigrades, nematomorphs and priapulids [93]. In invertebrate deuterostomes, the number of TLRs in echinoderms and amphioxus is expanded [64, 94, 95], which is in contrast to the limited number of TLRs in tunicates [96, 97]. Although the TLR sequences of many metazoans have been explored [7, 12-14], more protostome species must be surveyed to gain a better picture of the TLR evolution (Fig. 2).

Although the phylogenetic relationships of TLRs have been previously analyzed, these were mainly focused on vertebrate TLR evolution $[67,99]$ or including only few protostome species $[13,65,89]$. So far, the results are contradictory and are not sufficient to comprehend the detailed evolution of TLRs. For instance, Davidson et al. [65] suggested that TLRs are divided into three major clades, although the relationships between them remained unresolved. Brennan and Gilmore [13] suggested that TLRs cluster according to the TLR-type (P-type/mcc or V-type/scc) and Liu et al. [67] suggested that both TLR types would be widespread in invertebrates. Furthermore, Luo et al. [89] showed lineagespecific expansions of TLRs in some trochozoan groups (phoronids, nemerteans and brachiopods). Thus, phylogenetic analyses including TLRs of species representing a broader metazoan diversity are lacking. In this study, we aim to reconstruct the TLR evolution by searching for TLRs in under-represented metazoan clades and performing a phylogenetic analysis including TLRs of species from the four main metazoan clades (cnidarians, spiralians, ecdysozoans and deuterostomes). Moreover, we aim to reconstruct the early TLR function by analyzing their expression during the course of development in four protostome species.

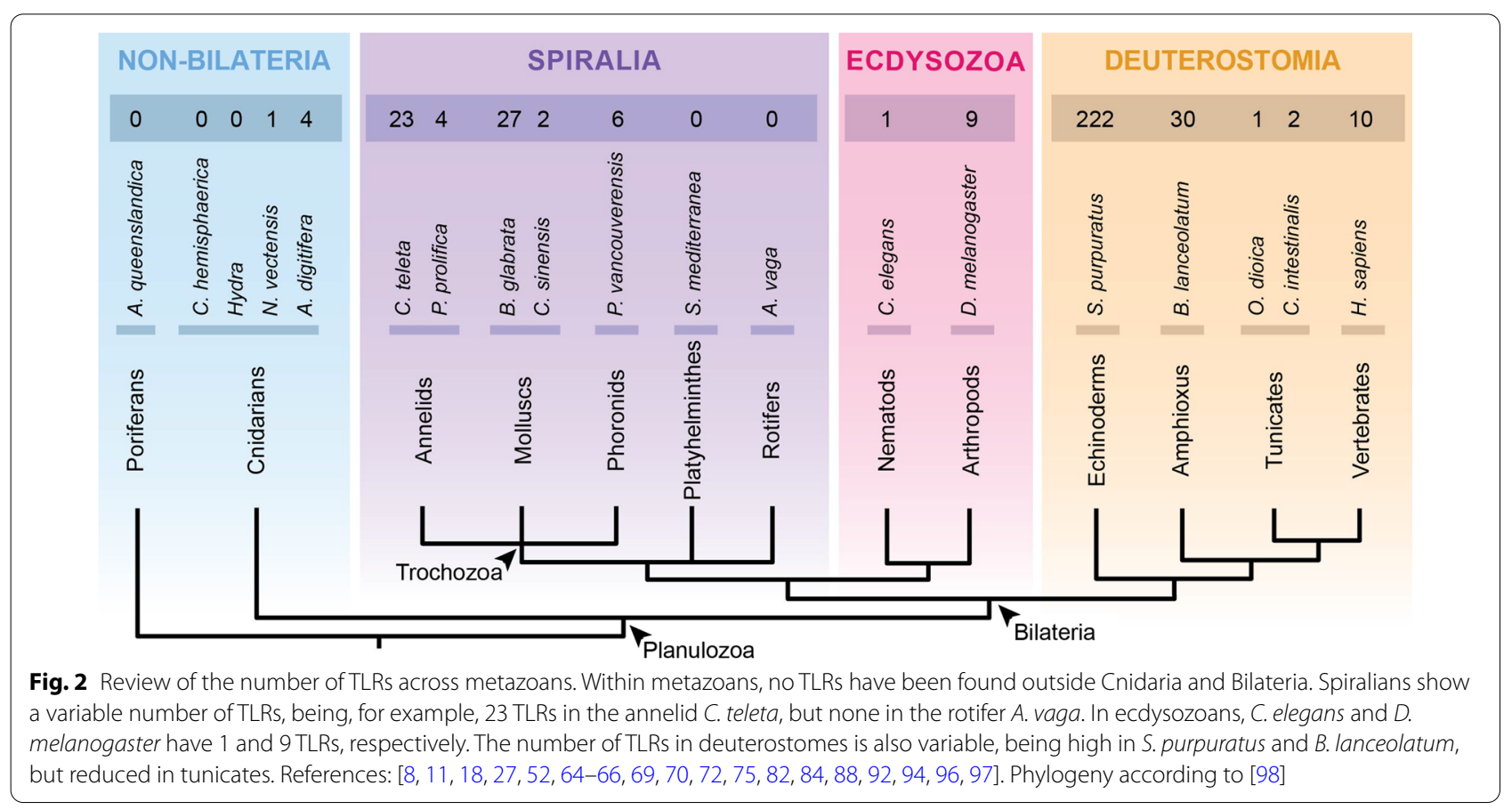




\section{Results}

Our genome and transcriptomic surveys revealed a total of 198 TLRs in 25 species (Table 1, Fig. 3). No TLRs were found in 20 species. Additionally, our analysis also revealed a large number of TLR-like proteins (TIR-only or LRR-only). However, only sequences containing a TIR domain, a transmembrane domain and, at least, one LRR domain were considered as criteria for TLRs. In this regard, we would like to mention the limitation of our method, as when performing transcriptomic surveys some TLRs could have been under-detected due to no expression in the tissue or the developmental stage sequenced, or because partial sequences obtained from transcriptomes could have been misclassified into TLR-like when an LRR domain, the transmembrane domain and the TIR domain were not present together in one sequence.

\section{TLRs are absent in the genomes and transcriptomes of xenacoelomorphs and in some spiralians}

Our surveys revealed that TLRs are absent in the genomes and transcriptomes of all Xenacoelomorpha, Platyhelminthes, Cycliophora, Micrognathozoa and Gastrotricha species analyzed (Table 1). Furthermore, TLRs are also absent in the transcriptomes of all the rotifer species investigated, except for E. senta (Table 1, Fig. 3). Moreover, although TLRs were present in the bryozoan $M$. membranacea, they were not found in the transcriptome of the bryozoan $B$. neritina. However, although TLRs were not detected, TLR-like proteins were present in all these animal groups (data not shown).

\section{The number of TLRs detected in members of Ecdysozoa is low when compared to Spiralia and Deuterostomia} The TLR survey of the ecdysozoan genomes and transcriptomes revealed only one TLR for the tardigrade, nematode, and onychophoran species analyzed (Table 1, Fig. 3). Furthermore, we detected up to 4 different TLRs in priapulids, 2 in loriciferans, and 5 in arthropods.

\section{Multiple TLRs are detected in trochozoan species}

TLRs were found in the genomes/transcriptomes of all trochozoan species analyzed (Table 1, Fig. 3). Our results reveal that, in general, multiple TLRs are present in highly variable numbers in trochozoan species. The number of TLRs is not reflected by the phylogeny, meaning that species belonging to a same clade do not have a more similar number of TLRs than species belonging to another clade. This is explained by the multiple duplications and losses that have independently occurred in the
Toll receptor family during trochozoan evolution $[13,65$, 89].

\section{P-type/mcc and V-type/scc are not specific for any planulozoan clade}

Previous studies suggest that V(ertebrate)-type/scc and $\mathrm{P}$ (rotostome)-type/mcc TLRs are restricted to vertebrates and protostomes, respectively [64]. However, our results show that both, P-type/mcc and V-type/scc type TLRs, are present in cnidarians, spiralians, ecdysozoans, and deuterostomes (Table 1; Additional file 1: Table S1). V-type/scc TLRs are the most abundant TLR type in the spiralian species analyzed. However, many spiralians also have several P-type/mcc TLRs. P-type/mcc TLRs are the predominant TLR type in the ecdysozoan species included in this analysis. For nematodes, tardigrades and onychophorans, which only have one TLR, this TLR was always classified as P-type/mcc. Ecdysozoan species analyzed with more than one TLR have one or more P-type/ mcc TLRs and only one V-type/scc. Although the vertebrate TLR complement seems to only contain V-type/ scc TLRs [14, 67, 119, 120], P-type/mcc TLRs are also present in other deuterostomes, such as the tunicate $C$. intestinalis [97] and the echinoderm S. purpuratus [64] (Table 1, Additional file 1: Table S1). This suggests that P-type/mcc TLRs were lost in the lineage to the Craniata.

\section{TLRs form three clades}

Our phylogenetic analysis showed that TLRs group into three clades (Fig. 4A), which we named clade $\alpha$ (89 TLRs), clade $\beta$ (102 TLRs) and clade $\gamma$ (79 TLRs). Although these three clades are supported with support values $>60$, some of the internal nodes have low support values $(<60)$. The phylogenetic analysis showed that clades $\beta$ and $\gamma$ are sister clades and together form the sister group to clade $\alpha$. All three clades contain both P-type/ mcc and V-type/scc TLRs, which makes it difficult to reconstruct whether P-type/mcc or V-type/scc show the ancestral state of TLRs. Furthermore, 2 deuterostome TLRs (from H. sapiens and C. intestinalis) and 11 spiralian TLRs ( 2 from species of mollusks and 9 from brachiopods) could not be assigned to any of the above clades. The 9 brachiopod TLRs form a clade with a high support value ( $>60$ ), but do not group with either the mollusk or the deuterostome sequences. This TLR brachiopod clade is the sister clade to the three main clades $(\alpha, \beta$ and $\gamma)$. For these sequences, the alignment showed brachiopodspecific deletions in the amino acid positions 150-220 that are not present in the TLRs belonging to the three main clades (Additional file 2: Fig. S1). To investigate whether this insertion is causing the clustering of the TLRs into three clades, we performed a second phylogenetic analysis (Additional file 3: Fig. S2) with the same 
Table 1 TLR genome/transcriptome survey results and classification of TLRs included in the phylogenetic analysis

\begin{tabular}{|c|c|c|c|c|c|}
\hline Species & TLRs & V-type/scc & P-type/mcc & NC & References \\
\hline \multicolumn{6}{|l|}{ Cnidaria } \\
\hline Nematostella vectensis & 1 & 0 & 1 & 0 & L: [27] \\
\hline Acropora digitifera & 4 & 1 & 3 & 0 & L: [72] \\
\hline Acropora millepora & 1 & 0 & 1 & 0 & L: [72] \\
\hline Orbicella faveolata & 1 & 0 & 1 & 0 & L: [83] \\
\hline \multicolumn{6}{|l|}{ Xenacoelomorpha } \\
\hline Xenoturbella profunda & 0 & 0 & 0 & 0 & G: Unpublished \\
\hline Hofstenia miamia & 0 & 0 & 0 & 0 & G: GCA004352715 \\
\hline Praesagittifera naikaiensis & 0 & 0 & 0 & 0 & G: PRJDB7329 \\
\hline Isodiametra pulchra & 0 & 0 & 0 & 0 & G: Unpublished \\
\hline Meara stichopi & 0 & 0 & 0 & 0 & G: Unpublished \\
\hline Convolutriloba macropyga & 0 & 0 & 0 & 0 & T: [100] \\
\hline \multicolumn{6}{|l|}{ Spiralia } \\
\hline \multicolumn{6}{|l|}{ Bryozoa } \\
\hline Membranipora membranacea & 6 & 4 & 1 & 1 & T: SRX1121923 \\
\hline Bugula neritina & 0 & 0 & 0 & 0 & $\mathrm{~T}:[101]$ \\
\hline \multicolumn{6}{|l|}{ Cycliophora } \\
\hline Symbion pandora & 0 & 0 & 0 & 0 & T: [102] \\
\hline \multicolumn{6}{|l|}{ Annelida } \\
\hline Galathowenia oculata & 39 & 18 & 12 & 9 & T: Unpublished \\
\hline Eisenia fetida & 11 & 0 & 1 & 10 & T: SRX3108745 \\
\hline Helobdella robusta & 4 & 1 & 3 & 0 & G: [103] \\
\hline Phyllochaetopterus prolifica & 3 & 1 & 0 & 2 & L: [66] \\
\hline \multicolumn{6}{|l|}{ Mollusca } \\
\hline Crassostrea gigas & 12 & 10 & 2 & 0 & G: [104] \\
\hline Octopus bimaculoides & 9 & 1 & 6 & 2 & G: [105] \\
\hline Cyclina sinensis & 2 & 1 & 1 & 0 & L: [88] \\
\hline Leptochiton rugatus & 1 & 0 & 0 & 1 & L: [66] \\
\hline Biomphalaria glabrata & 27 & 16 & 10 & 1 & G: [87]/NCBI \\
\hline \multicolumn{6}{|l|}{ Brachiopoda } \\
\hline Terebratalia transversa & 15 & 4 & 4 & 7 & Т: [100] \\
\hline Hemithris psittacea & 6 & 3 & 1 & 2 & T: [66] \\
\hline Lingula anatina & 25 & 15 & 7 & 3 & G: [106] \\
\hline \multicolumn{6}{|l|}{ Micrognathozoa } \\
\hline Limnogathia maerski & 0 & 0 & 0 & 0 & T: SRX1121929 \\
\hline \multicolumn{6}{|l|}{ Gastrotricha } \\
\hline Lepidodermella squamata & 0 & 0 & 0 & 0 & Т: [107] \\
\hline Macrodasys sp & 0 & 0 & 0 & 0 & T: [108] \\
\hline Megadasys sp & 0 & 0 & 0 & 0 & T: [108] \\
\hline Diuronotus aspetos & 0 & 0 & 0 & 0 & T: SRX1121926 \\
\hline Mesodasys laticaudatus & 0 & 0 & 0 & 0 & T: SRX872416 \\
\hline \multicolumn{6}{|l|}{ Nemertea } \\
\hline Lineus longissimus & 10 & 7 & 2 & 1 & Т: [100] \\
\hline Lineus ruber & 6 & 2 & 3 & 1 & T: Unpublished \\
\hline Notospermus geniculatus & 7 & 5 & 1 & 1 & G: [89] \\
\hline Paranemertes peregrina & 2 & 1 & 0 & 1 & L: [66] \\
\hline \multicolumn{6}{|l|}{ Phoronida } \\
\hline Phoronopsis harmeri & 2 & 0 & 1 & 1 & T: SRX1121914 \\
\hline Phoronis australis & 24 & 14 & 8 & 2 & G: [89] \\
\hline
\end{tabular}


Table 1 (continued)

\begin{tabular}{|c|c|c|c|c|c|}
\hline Species & TLRs & V-type/scc & P-type/mcc & NC & References \\
\hline Phoronis psammophila & 3 & 1 & 1 & 1 & L: [66] \\
\hline Phoronis vancouverensis & 6 & 5 & 0 & 1 & L: [66] \\
\hline \multicolumn{6}{|l|}{ Platyhelminthes } \\
\hline Macrostomum lignano & 0 & 0 & 0 & 0 & G: [109] \\
\hline Echinococcus multilocularis & 0 & 0 & 0 & 0 & G: [110] \\
\hline Hymenolepis microstoma & 0 & 0 & 0 & 0 & G: [1 10] \\
\hline \multicolumn{6}{|l|}{ Rotifera } \\
\hline Epiphanes senta & 1 & 1 & 0 & 0 & T: Unpublished \\
\hline Rotaria tardigrada & 0 & 0 & 0 & 0 & $\mathrm{~T}:[111]$ \\
\hline Echinorhynchus gadi & 0 & 0 & 0 & 0 & T: SRX1121912 \\
\hline Macracanthorhynchus hirudinaceus & 0 & 0 & 0 & 0 & T: [108] \\
\hline \multicolumn{6}{|l|}{ Ecdysozoa } \\
\hline \multicolumn{6}{|l|}{ Priapulida } \\
\hline Priapulus caudatus & 3 & 0 & 3 & 0 & $\mathrm{~T}:[100]$ \\
\hline Halicryptus spinulosus & 4 & 1 & 3 & 0 & T: [100] \\
\hline \multicolumn{6}{|l|}{ Tardigrada } \\
\hline Hypsibius exemplaris & 1 & 0 & 1 & 0 & G: [112] \\
\hline Ramazzottius varieornatus & 1 & 0 & 1 & 0 & G: [113] \\
\hline \multicolumn{6}{|l|}{ Onychophora } \\
\hline Peripatopsis capensis & 1 & 0 & 0 & 1 & T: [114] \\
\hline \multicolumn{6}{|l|}{ Nematoda } \\
\hline Loaloa & 1 & 0 & 1 & 0 & G: [115] \\
\hline Onchocerca volvulus & 1 & 0 & 1 & 0 & G: [116] \\
\hline Caenorhabditis elegans & 1 & 0 & 1 & 0 & L: NCBI \\
\hline \multicolumn{6}{|l|}{ Loricifera } \\
\hline Armorloricus elegans & 2 & 1 & 1 & 0 & T: SRX1120677 \\
\hline \multicolumn{6}{|l|}{ Arthropoda } \\
\hline Daphniapulex & 5 & 2 & 3 & 0 & G: [117] \\
\hline Drosophila melanogaster & 9 & 1 & 8 & 0 & L: NCBI \\
\hline Ixodes scapularis & 5 & 1 & 3 & 1 & L: [118] \\
\hline \multicolumn{6}{|l|}{ Deuterostomia } \\
\hline \multicolumn{6}{|l|}{ Tunicata } \\
\hline Ciona intestinalis & 2 & 1 & 1 & 0 & L: [97] \\
\hline Oikopleura dioica & 1 & 1 & 0 & 0 & L: [96] \\
\hline \multicolumn{6}{|l|}{ Echinodermata } \\
\hline Strongylocentrotus purpuratus & 8 & 7 & 1 & 0 & L: [64] \\
\hline \multicolumn{6}{|l|}{ Craniata } \\
\hline Homo sapiens & 10 & 10 & 0 & 0 & L: NCBI \\
\hline
\end{tabular}

NC column indicates the number of TLRs that could not be classified for each species. In the reference column it is indicated whether the survey was performed in a genome (G) or a transcriptome ( $\mathrm{T}$ ), followed by the reference or NCBI accession number in case the genome/transcriptome was published. TLR sequences extracted directly from the literature and, therefore, were not obtained in our genomic and transcriptomic surveys, are indicated with an L. NCBI indicates that sequences were collected individually from NCBI database. For further details, see Additional file 4: Table S2

parameters of the main analysis (Fig. 4A) but excluding the 150-200 amino acid region. The second analysis (Additional file 3: Fig. S2) is able to reconstruct clade $\alpha$ with high support value (>60). However, clade $\gamma$ is nested within clade $\beta$ and both of them have low support values $(<60)$. In the second analysis (Additional file 3: Fig. S2), as in the main analysis (Fig. 4), the 9 brachiopod sequences cluster together and form the sister clade to the three main clades. However, in the analysis shown in Additional file 3: Fig. S2, the mollusk and deuterostome sequences are included in the clade $\gamma$. In the main analysis (Fig. 4A), no distinctive motifs were observed in the alignment that justify the exclusion of these sequences from the main clades. 


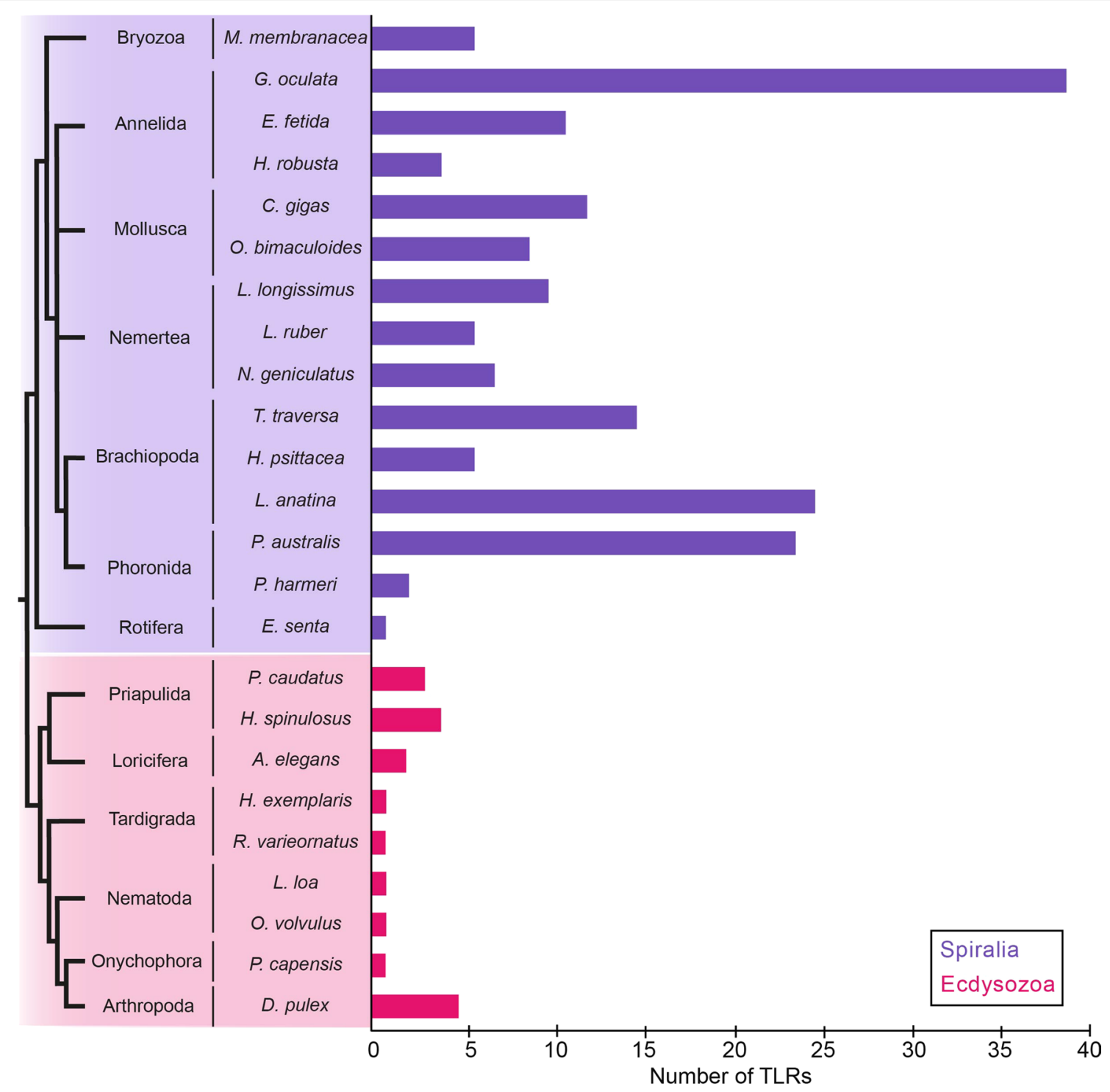

Fig. 3 Number of TLRs in species included in the genome/transcriptome analyses. In general, the number of TLRs in spiralians (purple) is higher and more variable between species when compared to ecdysozoans (magenta). Species for which TLRs were not detected are excluded from the graph

(See figure on next page.)

Fig. 4 TLR phylogenetic analysis and distribution of P-type/mcc or V-type/scc. A Phylogenetic analysis of TLRs based on maximum likelihood. Bootstrap values are indicated next to the main nodes, being all nodes with bootstrap values $>60$ marked with full dots and colored differently according to the support values. Tip labels contain an abbreviation of the species name and the gene name given in this study (for sequences searched de novo here) or in the original study (for sequences obtained from the literature). Numbers in the gene name do not imply gene orthology. Species abbreviations: Ael: A. elegans; Ad: A. digitifera; Am: A. millepora; Bgl: B. glabrata; Ce: C. elegans; Cgi: C. gigas; Ci: C. intestinalis; Cs: C. sinensis; Dm: D. melanogaster; Dpu: D. pulex; Efe: E. fetida; Ese: E. senta; Goc: G. oculata; Hex: H. exemplaris; Hps: H. psittacea; Hro: H. robusta; Hsa: H. sapiens; Hsp: H. spinulosus; Isc: I. scapularis; Mme: M. membranacea; Nge: N. geniculatus; Nv: N. vectensis; Lan: L. anatina; Lloa: L. loa; Llon: L. Iongissimus; Lrub: L. ruber; Lrug: L. rugatus; Obi: O. bimaculoides; Od: O. dioica; Of: O. faveolata; Ovo: O. volvulus; Pau: P. australis; Pcap: P. capensis; Pcau: P. caudatus; Phe: P. hermeri; Ppe: P. peregrina; Ppr: P. prolifca; Pps: P. psammophila; Pva: P.vancouverensis; Rva: R. varieornatus; Sp: S. purpuratus; Ttr: T. transversa. B Presence/absence of the TLR clades in the metazoan groups included in our study 


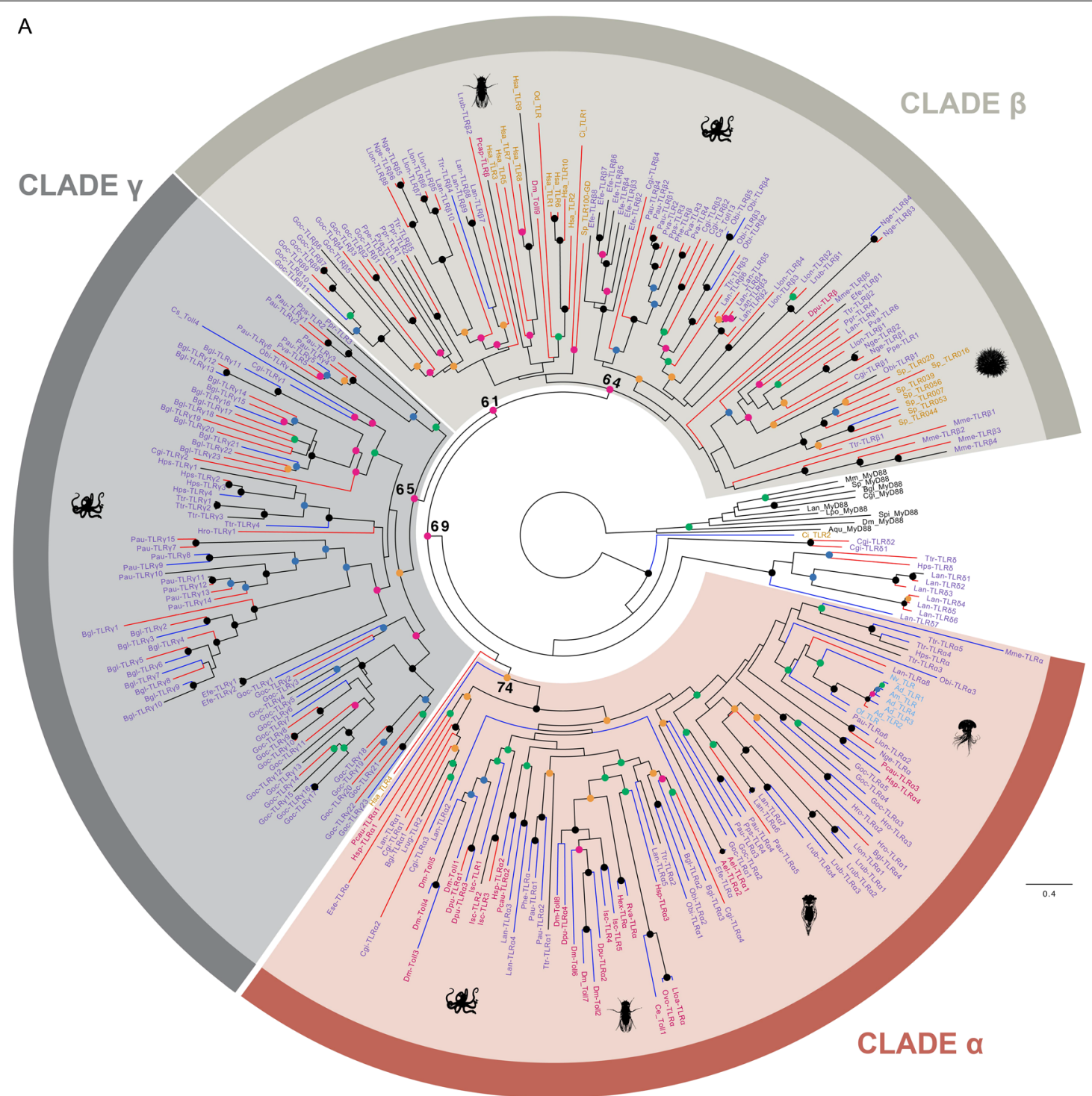

\begin{tabular}{|c|c|c|c|c|c|c|c|}
\hline \multicolumn{3}{|c|}{ Genes } & \multicolumn{2}{|c|}{ Branches } & \multicolumn{3}{|c|}{ Nodes (Support values) } \\
\hline $\begin{array}{l}\text { Cnidaria } \\
\text { Spiralia }\end{array}$ & $\begin{array}{l}\text { Ecdysozoa } \\
\text { Deuterostomia }\end{array}$ & Outgroup & $\begin{array}{l}\text { - P-type/mcc TLRs } \\
\text { - V-type/scc TLRs }\end{array}$ & — Unclassified TLRs & $\begin{array}{l}\text { - } 98-100 \% \\
\text { - } 90-97 \%\end{array}$ & $\begin{array}{l}\text { - } 80-89 \% \\
\text { - } 70-79 \%\end{array}$ & - $60-69 \%$ \\
\hline
\end{tabular}

B

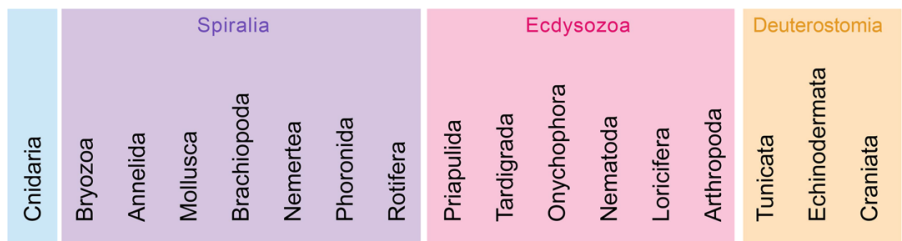

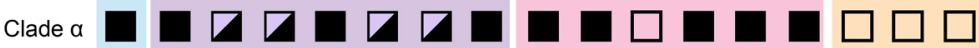

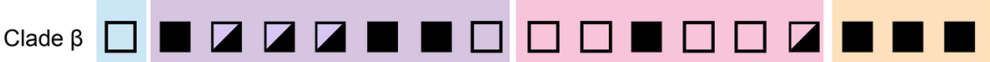
Clade y $\square \square \square \square \square \square \square \square \square \square \square \square \square \square \square \square \square$ 
Clade $\alpha$ includes TLRs from all cnidarian, spiralian and ecdysozoan species analyzed, except for the onychophoran TLR (Fig. 4). Because all cnidarian TLRs cluster together, it is likely that only one TLR was present in the last common ancestor of Cnidaria. Clade $\beta$ is formed by TLRs belonging to deuterostomes, spiralians and three ecdysozoans (two arthropods and the onychophoran TLR) (Fig. 4). This suggests that at least the ancestral TLR of Clade $\beta / \gamma$ was already present in the last common ancestor of Nephrozoa (Protostomia + Deuterostomia). Furthermore, lineage-specific expansions of clade $\beta$ TLRs are detected in spiralians and deuterostomes. Clade $\gamma$ TLRs are present in all trochozoan groups except for the nemertean species analyzed (Fig. 4). Clade $\gamma$ contains TLRs that radiated independently in several lineages. Our alignment shows that 159/181 TLRs belonging to the clades $\beta$ and $\gamma$ contain an insertion of 6 amino acids in the positions 349-354 (Additional file 2: Fig. S1). In Clade $\alpha$, this insertion is only present in Pcau-TLR $\alpha 1$, the sister TLR to all the remaining TLRs belonging to this clade. To exclude that this insertion causes the clustering in three distinct clades, we performed a third phylogenetic analysis (Additional file 5: Fig. S3), in which we applied the same parameters as in the main analysis -shown in Fig. 4A- but eliminated the 6 amino acid insertion regions. In the third analysis (Additional file 5: Fig. S3), the three clades could be reconstructed with good support values $(>60)$. However, due to low support values $(<60)$, the relationship between the clades could not be resolved. Moreover, the clustering of the TLRs into the three clades $(\alpha, \beta, \gamma)$ was maintained with respect to the main analysis (Fig. 4A, Additional file 5: Fig. S3), except for eight phoronid and one human sequences. In the main analysis (Fig. 4A), the phoronid sequences cluster together within clade $\gamma$, with high support values (>60). This clade of phoronid TLRs is the sister clade to all remaining TLRs in clade $\gamma$. Nevertheless, in the third analysis (Additional file 5: Fig. S3), these phoronid TLR sequences constitute a well-supported $(>60)$ clade within clade $\beta$, but it is not the sister clade to the remaining TLRs in this clade. In the main analysis (Fig. 4A), the human sequence is not included in any of the three main clades, but in the third analysis (Additional file 5: Fig. S3) it does cluster in clade $\alpha$.

\section{TLRs are expressed during development}

in the ecdysozoans $P$. caudatus and H. exemplaris and in the spiralians $C$. gigas and $T$. transversa

In order to study the temporal expression of TLRs during ontogeny, we analyzed stage-specific transcriptomes of the priapulid P. caudatus [121], the tardigrade $H$. exemplaris [122], the mollusk C. gigas [104] and the brachiopod T. transversa [123]. All the analyses were performed using both RSEM [124] and kallisto [125] methods.

The expression of the only TLR present in $H$. exemplaris was analyzed in stage-specific transcriptomes of 19 stages (one biological replicate) (Fig. 5A; Additional file 6: Table S3) [122]. Expression of TLR $\alpha$ was detected $(\mathrm{TMM} \geq 0.15)$ in time windows during development (zygote, morula, gastrula, elongation, segmentation and differentiation).

Three TLRs were identified in P. caudatus transcriptomic survey (Table 1). The expression of these TLRs was analyzed in five embryonic stages (two biological replicates) (Additional file 7: Table S4) [121]. Our results indicate that all three TLRs found in the transcriptomic survey are expressed during embryonic development (TMM $\geq 0.15$ ). Pca-TLR $\alpha 1$ and Pca-TLR $\alpha 2$ are expressed in all developmental stages analyzed, whereas Pca-TLR 3 is expressed only in the later embryonic stages (Fig. 5B; Additional file 7: Table S4).

The expression of the 12 C. gigas TLRs (Table 1) was analyzed in stage-specific transcriptomes of 19 stages (one biological replicate) (Additional file 8: Table S5) [104]. Our results show that at 11 of the 12 TLRs are expressed during development (Fig. 5C; Additional file 8: Table S5). Some TLRs are expressed throughout develop-

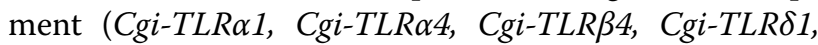

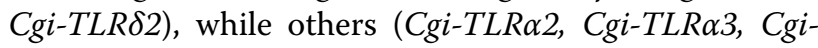
TLRß1, Cgi-TLRß2, Cgi-TLRY1, Cgi-TLR 2 ) are only expressed at certain developmental stages. Cgi-TLR $\beta 3$ expression was not detected at any of the stages analyzed.

15 TLRs were found in our transcriptome survey of T. transversa (Table 1). Expression of these TLRs was analyzed in stage-specific transcriptomes of 12 developmental stages (with two biological replicates) [123]. Our results suggest that at least 12 of the 15 TLRs are expressed at certain stages during $T$. transversa development (Fig. 5D; Additional file 9: Table S6). Ttr-TLR $\alpha$, Ttr-TLR 5 , Ttr-TLR $\beta 1, T t r-T L R \beta 4, T t r-T L R \beta 5$, and Ttr-TLR $\delta$ expression is detected in time windows during embryonic and larval stages. All these genes, except Ttr-TLR $\beta 5$, are expressed in juveniles. For some genes (Ttr-TLR $\alpha$ 4, Ttr-TLR $\beta 2$, Ttr-TLRß3, and Ttr-TLR $\gamma 4$ ), expression was detected throughout development. Moreover, expression was not detected at the embryonic and larval stages analyzed for Ttr-TLR $\alpha 1$, Ttr-TLR 1 , TtrTLR 22 and Ttr-TLR 3 . Similarly, Ttr-TLR $\alpha 3$ expression was only detected in the competent larvae and in the juveniles.

Our analyses show that TLRs are expressed during the development of the spiralians $T$. transversa and $C$. gigas and the ecdysozoans $P$. caudatus and $H$. exemplaris. These analyses show that the TLRs expressed during 
A

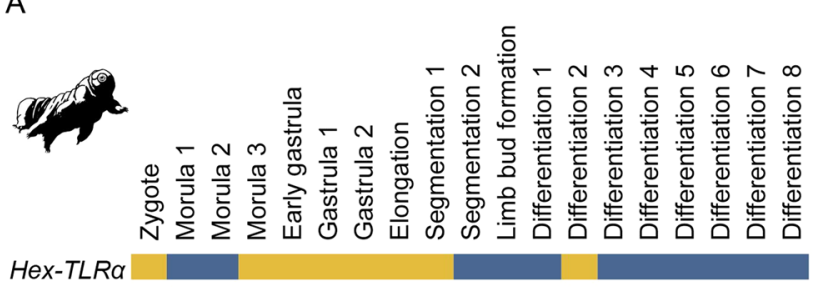

B

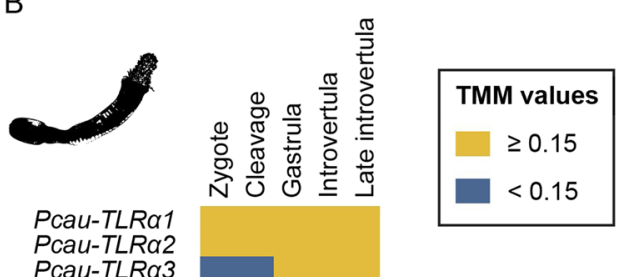

D

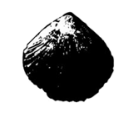

cau-TLRa3

\begin{tabular}{ll} 
Embryonic stages & $\begin{array}{l}\text { Larval } \\
\text { stages Juvenile }\end{array}$ \\
\hline
\end{tabular}

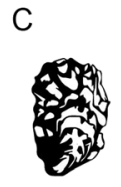

Embryonic stages

Larval stages

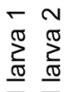

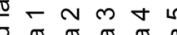
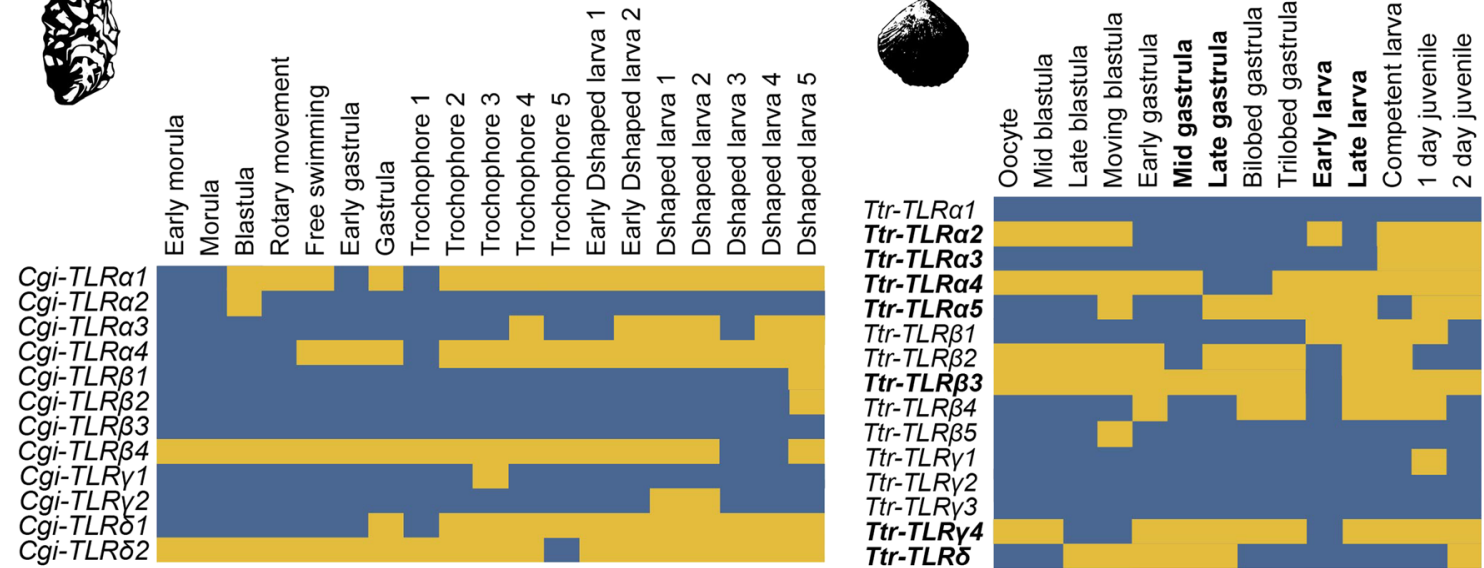

Fig. 5 TLR expression in developmental stage-specific transcriptomes of (A) H. exemplaris, (B) P. caudatus, C C. gigas and (D) T. transversa. Heatmaps corresponding to the average of the RSEM analyses are shown. For heatmaps corresponding to Kallisto analyses see Additional files 6, 7, 8 and 9: Tables S3-S6. Bold indicates stages and genes for which in situ hybridization was performed. TMM: Trimmed means of M values

development are not restricted to one TLR clade in the tree shown above, but they are found in all three main clades (e.g. Ttr-TLR $\alpha$, Ttr-TLRß3, Cgi-TLRY1).

Furthermore, in order to validate our stage specific transcriptome results, we performed whole mount in situ hybridization (WMISH) for the $T$. transversa mRNAs of TLR $\alpha 2, T L R \alpha 3, T L R \alpha 4, T L R \alpha 5, T L R \beta 3, T L R \gamma 4$ and $T L R \delta$ (Fig. 6). Consistently with our stage specific transcriptomic analysis, our WMISH results show that Ttr$T L R \alpha 2$ is not expressed at the early and late gastrula stages (Fig. 6A,B), but the expression is present in the mesoderm and in two pairs of lateral domains in early larvae (Fig. 6C). This gene is not expressed in late larvae
(Fig. 6D). In agreement with our stage specific transcriptomic analysis, we did not detect Ttr-TLR 3 neither in the gastrula nor in the larval stages analyzed (Fig. 6EH). Ttr-TLR $\alpha 4$ has a dynamic expression pattern during $T$. transversa development. This gene is expressed in the mesoderm at the early gastrula stage, but, consistent with the stage specific transcriptome analysis, it is not detected in late gastrulae (Fig. 6I-J). In early larvae, Ttr-TLR $\alpha 4$ is expressed in the inner lobe epithelium and in a medial V-shaped mesodermal domain (Fig. 6K). In late larvae, this gene is expressed in the brain and in the pedicle (Fig. 6L). Ttr-TLR 5 is not expressed at early gastrula stage (Fig. 6M), however, mRNA of Ttr-TLR $\alpha 5$

(See figure on next page.)

Fig. 6 Expression of TLRs during the development of the brachiopod T. transversa. Whole-mount in situ hybridization (WMISH) of TLRs in T. transversa embryos and larvae. Above the WMISH plates, there are schematic representations of each developmental stage analyzed. These representations are not to scale. The name of each gene is indicated in the rectangles on the left. All panels show dorso-ventral views and anterior to the top. Squares in the top-right of each plate indicate whether the expression was detected (yellow) or not (blue) in the stage-specific transcriptome analysis. Ectoderm, mesoderm and endoderm is indicated with blue, red and yellow arrowheads, respectively. The red and yellow arrowhead indicates endomesoderm. The ring-shape (indicated with white asterisks) staining present in the late larvae is background staining (Additional file 10: Fig. S4), probably related with the spicule formation described by Stricker and Reed [126-128]. Scale bar indicates $50 \mu \mathrm{m}$. al: apical lobe; bp: blastopore; cs: chaetal sacs; em: endomesoderm; me: mesoderm; ml: mantle lobe; pl: pedicle lobe 


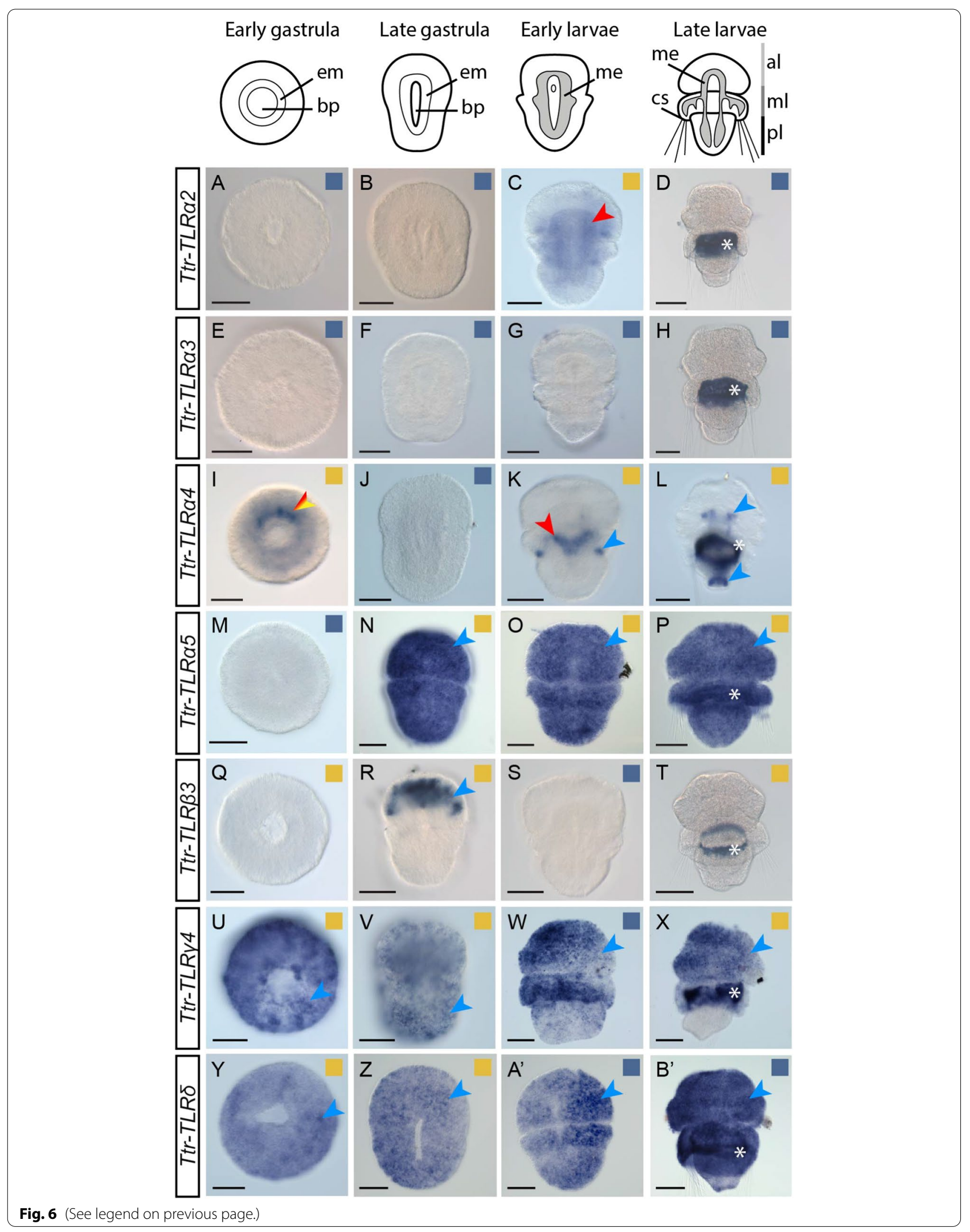


is detected in a uniform salt and pepper distribution at the late gastrula stage and the two larval stages for which WMISH was performed (Fig. 6N-P). Furthermore, although Ttr-TLR 33 expression was detected in early gastrula in the stage specific transcriptome analysis, expression was not detected by WMISH (Fig. 6Q). However, this gene is expressed in the anterior region of the animal in late gastrulae (Fig. 6R). Moreover, WMISH shows no expression of Ttr-TLR 33 in the early larvae (Fig. 6S). However, similarly to the early gastrula stage, Ttr-TLR 33 expression was detected in late larvae in the stage specific transcriptome analysis, but its expression was not detected by WMISH (Fig. 6T). The expression of Ttr-TLRY4 and Ttr-TLR $\delta$ have a uniformly salt and pepper distribution at the gastrulae and early larvae stages (Fig. 6U-W and $\mathrm{Y}-\mathrm{A}^{\prime}$ ). This salt and pepper transcript distribution is similar in late larvae, although it is absent from the pedicle lobes (Fig. 6X and B'). These results conflict with the stage specific transcriptome analyses, as, in this analysis, neither Ttr-TLRY4 expression was detected in the early larvae nor Ttr-TLR $\delta$ in any of the two larval stages tested. Differences between the results of both analyses could be explained by differences and variation of the developmental stages of the specimens used for the stage-specific transcriptome and the WMISH.

\section{Discussion}

\section{The evolution of the TLR family is characterized by losses,} expansion and conservation

As shown in previous studies, TLRs are absent in the Platyhelminthes S. mediterranea and S. mansoni [92]. Here, we show that this receptor family is also absent from the genomes of three other platyhelminth species (M. lignano, E. multilocularis and H. microstoma). Thus, TLRs are absent in species belonging to four different platyhelminth lineages (Macrostomorpha- $M$. lignano; Cestoda-E. multiocularis and H. microstoma; Tricladida-S. mediterranea; and Digenea-S. mansoni) suggesting that TLRs could have been lost during early platyhelminth evolution. This hypothesis is reinforced by the lack of TLRs in M. lignano, member of Macrostomorpha, an early-diverging platyhelminth lineage [107]. In rotifers, even though TLRs could not be detected in $A$. vaga [70], E. gadi, R. tardigrada and M. hirudinaceus, our transcriptome survey revealed one TLR in the monogonont rotifer E. senta. This suggests that TLRs would have been independently lost in some rotifer lineages. So far, we did not detect TLRs in the genomes and transcriptomes of the species belonging to Xenacoelomorpha, Cycliophora, Micrognathozoa, and Gastrotricha, suggesting that TLRs were lost in these lineages. How the immune response is achieved in animals that lack TLRs is unknown, but it could be triggered by other components of the Toll pathway - e.g. TLR-like molecules [14, 7072] -, similar to what has been shown for LRR-only TLRlike and TIR-only TLR-like in Hydra [75, 76].

Another outcome of this study is the remarkable expansion that the TLRs family exhibits in trochozoans. Evolution of this gene family in trochozoans is characterized by multiple duplications and losses, having as a consequence a very variable number of the TLRs complement in trochozoans. Moreover, in our phylogenetic analysis, TLRs of the same species and clades mostly group together, indicating the existence of multiple independent duplications (Fig. 4A). The same has been shown also in previous phylogenetic analyses of TLRs $[13,65,89]$.

In contrast to trochozoans, our results show that the number of TLR in ecdysozoans has been relatively conserved during evolution. At least, few TLR gene duplications have occurred in this lineage, including recent independent duplications in arthropods, priapulids or loriciferans.

\section{The evolution of the three clades $(\alpha, \beta, \gamma)$ of TLRs}

There are very few studies assessing the phylogenetic relationships of TLRs within the main metazoan clades (Fig. 7) [65, 89]. The study of Davidson et al. [65] recovered three clades of TLRs. However, the relationships between the clades remain unclear. Furthermore, the composition of the clades slightly differs in both analyses (e.g. while our study shows that deuterostome TLRs belong to one clade-clade $\beta$-their results suggest that deuterostome TLRs are present in two clades-clades A and B) [65]. However, their phylogenetic study is limited by the number of sequences and species included. Similar to Luo and Zheng [129]; and Luna et al. [130], our results suggest that ecdysozoan and deuterostome TLRs evolved independently from a common TLR precursor. However, our phylogenetic analysis has also some limitations, as the support values for the main clades are not optimal (with support values 61-74\%). This is also reflected by the rearrangement of the tree when the alignment is

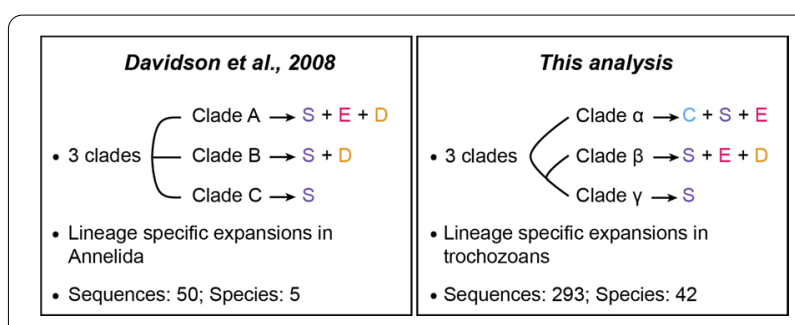

Fig. 7 Comparison between Davidson et al. [65] and this study. The main conclusions and the number of TLRs and species included in the two studies are compared. Cnidaria (C), Spiralia (S), Edysozoa (E) and Deuterostomia (D) 
modified for the phylogenetic analyses shown in Additional files 2, 3: Figs. S2 and S3.

Previous studies suggest that TLRs originated likely by the fusion of an LRR-only and a TIR-only TLR genes in the branch to the Planulozoa (Cnidaria + Bilateria) [7, 14, 67]. However, this hypothesis is challenged by the presence of TLRs in choanoflagellates, indicating that at least one TLR could be already present in the common ancestor of choanoflagellates and animals [68].

Our data suggests different hypothesis on how TLRs evolved within the animal lineages (Fig. 8, Additional file 11: Fig. S5). The main differences between these hypotheses reside in when the duplications that originated the ancestral genes for the TLR $\alpha, \beta$ and $\gamma$ clades (TLR-C $\alpha, T L R-C \beta$, and TLR-C $\gamma$, respectively) ocurred. First, from our data, we can hypothesize that there were present either one TLR (a TLR-C $\alpha / \beta / \gamma$ ) in the planulozoan common ancestor-hypothesis $1 \mathrm{~A}$-; while it could be also inferred that two TLRs (TLR-C $\alpha$ and TLR-C $C \beta / \gamma)$ were already present in the planulozoan common ancestor and $T L R-C \beta / \gamma$ was lost in cnidarians-hypothesis 1B -. Since cnidarian TLRs are well nested within clade $\alpha$ (Fig. 4A), we suggest that the most probable scenario is that the planulozoan common ancestor had already a $T L R-C \alpha$ and a $T L R-C \beta / \gamma$-hypothesis $1 \mathrm{~B}$-. Second, according to our analyses, the duplication of $T L R-C \beta / \gamma$ that gave raise to TLR-C $\beta$ and TLR-Cy could have occurred either in the nephrozoan common

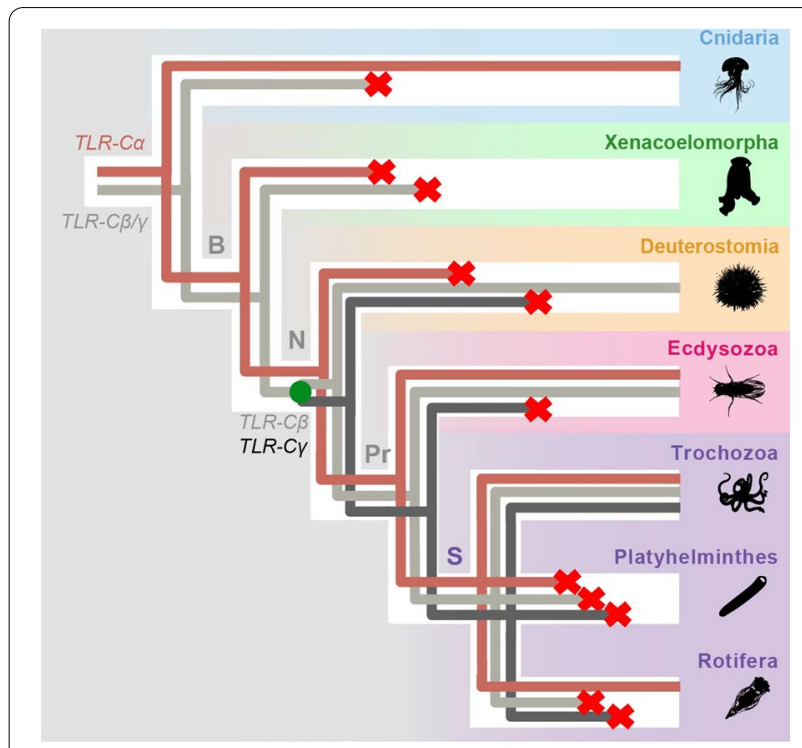

Fig. 8 Origin and evolution of TLRs. Gene lineages are depicted in different colors (TLR-Ca: light brown; $T L R-C \beta / \gamma$ and $T L R-C \beta$ : light grey; and $T L R-C \gamma$ : dark grey) within the metazoan tree. Gene losses are indicated with a cross. Phylogeny according to: [98]. For other hypotheses see Additional file 11: Fig. S5 ancestor-hypothesis $2 \mathrm{~A}$-, the spiralian common ancestor-hypothesis $2 \mathrm{~B}-$ or the trochozoan common ancestor-hypothesis $2 \mathrm{C}$-. Since TLR clade $\gamma$ is not nested within clade $\beta$, we suggest that the emergence of $T L R-C \beta$ and $T L R-C \gamma$ probably occurred in the nephrozoan common ancestor-hypothesis $2 \mathrm{~A}$-. The only possibility for clade $\beta$ and $\gamma$ to be sister clades (Fig. 4A) but have emerged after the split of deuterostome and protostome lineages would be if only one $T L R-C \beta / \gamma$ would be present until the point of the splitting event. Since duplications and losses have occurred frequently during TLR evolution, we suggest that the most probable scenario is that $T L R-C \beta$ and TLR-C $\gamma$ emerged in the nephrozoan common ancestor. In order to see other hypotheses for TLR evolution, see Additional file 11: Fig. S5.

Therefore, here we hypothesize that the planulozoan stem species already had two TLRs (Fig. 8, Additional file 11: Fig. S5B): a clade $\alpha$ type TLR gene $(T L R-C \alpha)$ and a proto-TLR gene of clades $\beta$ and $\gamma(T L R-C \beta / \gamma)$. This is supported by the fact that all cnidarian TLRs included in our analysis cluster in a monophyletic group within clade $\alpha$, which is consistent with the results of Brennan and Gilmore [13]. During cnidarian evolution, this gene was lost in some lineages, e.g. Hydra [75], Clytia [84], and multiplied in others, e.g. A. digitifera [72]. Furthermore, under this scenario, $T L R-C \beta / \gamma$ was presumably lost during early cnidarian evolution, as TLRs belonging to this clade are absent in all extant cnidarian analyzed. Moreover, after the split into the Xenacoelomorpha and the Nephrozoa lineages, both $T L R-C \alpha$ and $T L R-C \beta / \gamma$ were lost in xenacoelomorphs.

Before the split into the deuterostome and the protostome lineages, $T L R-C \beta / \gamma$ was duplicated in the lineage to the nephrozoan common ancestor, giving raise to the $T L R-C \beta$ and $T L R-C \gamma$ genes (Fig. 8). However, our results indicate that both TLR-C $\alpha$ and TLR-C $\gamma$ were lost during early deuterostome evolution. Later, expansions of $T L R-C \beta$ generated the TLR diversity found in deuterostomes. Furthermore, as vertebrate TLRs diversified within the vertebrate lineage, it is impossible to make one-to-one orthology gene assignments between the vertebrate TLRs and the invertebrate TLRs [67].

Similarly than the nephrozoan common ancestor, the protostome stem species and the spiralian stem species had likely at least one TLR belonging to each clade (Fig. 8). Our results show that only TLRs belonging to clades $\alpha$ and $\beta$ are present in ecdysozoans (Fig. 4), suggesting that $T L R-C \gamma$ was probably lost during early ecdysozoan evolution. Although, in general, the number of TLRs in ecdysozoans is low, few duplications of $T L R-C \alpha$ occurred in some lineages (e.g. arthropods, priapulids, loriciferans). Furthermore, our analysis shows that the surveyed priapulids, tardigrades, nematodes 
and loriciferan lack TLRs from clade $\beta$; whereas clade $\beta$ TLRs are present in the majority of the arthropods and in the onychophoran surveyed. This would imply that TLR clade $\beta$ would have been lost several times independently in the early branches and preserved in the other lineages $[98,131]$.

Within Spiralians, the evolution of TLRs followed different strategies in trochozoan and non-trochozoan organisms. In trochozoans, TLRs from the three clades were maintained (Fig. 8), followed by episodes of gene duplication that generated the large diversity of TLRs. These expansions could have occurred in correlation with the necessity to adapt to microbe rich environments [132, 133]. Nonetheless, all TLRs were lost in other non-trochozoan organisms (e.g. platyhelminthes). Losses of TLR $\beta$ and $\gamma$ also occurred in rotifers, although a TLR $\alpha$ gene is present in the monogont rotifer E. senta.

\section{Are protostome TLRs involved in immunity and development during ontogeny?}

TLRs are well known to play a key role in adult innate immunity in planulozoans [11, 22-26]. During ontogeny, this gene family has also been shown to be involved in a great number of developmental processes both in arthropods and vertebrates $[2,8,9,36,38,39,42,44-46]$. Here, we identify TLRs expressed during ontogeny in four protostome species (the ecdysozoans $H$. exemplaris and $P$. caudatus and the spiralians $C$. gigas and T. transversa) (Figs. 5 and 6). Expression of TLRs was observed for some TLRs in short developmental time windows (the H. exemplaris Hex-TLR $\alpha$; the C. gigas Cgi-TLR $\alpha 2$, Cgi-

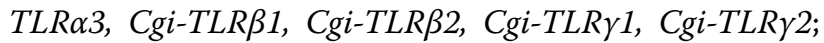
and the T. transversa Ttr-TLR $\alpha 2$, Ttr-TLR $\alpha$, Ttr-TLR $\beta 1$, Ttr-TLR 44 , Ttr-TLR $\beta$ ), suggesting a possible role of these genes in development, as genes involved in developmental processes are usually expressed for defined periods of time in tissues in order to participate in specific developmental processes [134-136]. For instance, expression during early embryonic stages of the T. transversa Ttr-TLR 2 (Fig. 5) might suggest its involvement in dorso-ventral axis specification, as it has been shown for the Drosophila Toll $[8,9]$. Later, in the early larvae, transcription of this gene is transiently activated in the mesoderm (Figs. 5 and 6), suggesting that this gene might be also involved in mesoderm development. However, our analyses do not exclude the possibility that these genes might also be involved in immunity, as these TLRs could have a dual role, as it has been shown for the Drosophila Toll [10] and the only TLR in the cnidarian $N$. vectensis [27]. Discerning the role of TLRs expressed in broad time windows or during the whole development (the three $P$. caudatus TLRs; the C. gigas Cgi-TLR $\alpha 1$, Cgi-TLR 4 , Cgi-

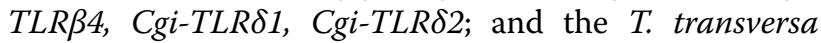

Ttr-TLR $\alpha$, Ttr-TLR $\beta 2, \quad T t r-T L R \beta 3$, and Ttr-TLR $\gamma 4$ ) is complex, as these genes could be involved either in immunity or in development, or both. However, detection of immune processes in our analyses is not possible with the data available. Therefore, further investigations are required to gain more knowledge on functions of TLRs during development. Immune roles of the TLRs during ontogeny should not be underestimated: Many marine invertebrate embryos and larvae live in environments rich in microbial pathogens [137, 138]. Pathogens cause mortality of embryos and larvae but also provoke anomalies during development [139, 140]. Therefore, these embryos and larvae need immune defenses to fight pathogens [138]. Actually, few studies have shown that the Toll pathway is involved in immunity during ontogeny in arthropods, mollusks and amphioxus [18, 140142], and other immune-related genes have also been found to be involved in immunity during mollusk and echinoderm development [141, 143-145]. Additionally, in planulozoans it has been shown that TLRs are involved in adult immunity [11, 22-26]. Thus, TLRs are probably also involved in immunity during ontogeny in species across the metazoan tree.

\section{Conclusions}

Based on our data we propose a scenario in which a $T L R-C \alpha$ and a $T L R-C \beta / \gamma$ were present in the planulozoan common ancestor. However, the later was lost during early cnidarian evolution. $T L R-C \beta / \gamma$ later duplicated in the nephrozoan common ancestor, giving raise to $T L R-C \beta$ and TLR-CY. Duplications and losses characterize the evolution of the three TLR clades in the main metazoan groups. The TLR complement was expanded during Trochozoa evolution, while it was lost in some non-trochozoan spiralian lineages (e.g. platyhelminths, cycliophorans, micrognathozoans, gastrotrichs and some rotifers). Ecdysozoans possess a low number of Clade $\alpha$ and Clade $\beta$ TLRs; whereas all deuterostome TLRs belong to clade $\beta$, being originated by radiations in the different lineages. Furthermore, our data shows that TLRs are expressed during ontogeny in two ecdysozoan and two spiralian species, suggesting that some of these genes could be likely involved in development.

\section{Materials and methods}

\section{Genomic and transcriptomic surveys}

We surveyed TLRs 20 genomes and 25 transcriptomes (Additional file 4: Table S2). Overall, only high-quality transcriptomes (Complete BUSCO gene values $>70 \%-$ Additional file 4: Table S2) were selected, but lower quality transcriptomes were also included when they represented a species from a low investigated clade (e.g. the loriciferan A. elegans transcriptome (Complete 
BUSCO gene value $36.2 \%)$ ). In order to search for the TLR sequences, hmmer profiles for the TIR and the LRR domains were generated using HMMER software version 3.2.1 [146] (www.hmmer.org). The hmmer profile for the TIR domain was compared to each genome/transcriptome using the hmmersearch function of HMMER in order to obtain a database of proteins containing the TIR domain. Next, the LRR hmmer profile was also compared to the TIR domain-containing sequences database by using hmmersearch. These sequences were validated by BLAST [147] (www.blast.ncbi.nlm.nih.gov) and SMART [148, 149] (http://smart.embl.de/). Sequences from the same species with $>90 \%$ similarity were considered to be polymorphisms or isoforms and only one of them was considered for the analyses.

\section{Phylogenetic analysis}

The phylogenetic analysis was performed including TLRs obtained from the genome/transcriptome surveys, from NCBI database and from the literature. Since the MyD88 protein contains a TIR domain, this protein was selected as an outgroup. All sequences included in the phylogenetic analyses are found in Additional file 1: Table S1. The TLR and MyD88 sequences were aligned using MAFFT software version 7 applying the L-INS-I algorithm [150]. The alignment was trimmed manually in order to obtain a fragment containing one LRR domain, the transmembrane domain, and the TIR domain. This was followed by a second trimming step performed with TrimAl software version 1.2 using the gappyout trimming model [151]. The final alignment used to perform the phylogenetic analysis contains 375 amino acids. The maximum likelihood phylogenetic analysis was performed using IQ-TREE software [152] in the CIPRES Science Gateway V.3.3 [153] (http://www.phylo.org). LG + R8 was selected as the best-fit model (according to BIC (Bayesian Information Criterion) [154]) and was applied for the phylogenetic reconstruction. Bootstrap values were calculated running 1000 replicates using ultrafast bootstrap.

\section{TLR classification}

TLR sequences from the genomic/transcriptomic surveys, as well as the ones obtained from the literature and NCBI database, were classified into P-type/mcc and V-type/scc. In order to do so, the number of LRR domains was analyzed with LRRfinder software [155] (http://www.lrrfinder.com). Next, sequences were classified applying the same criteria followed by Brennan and Gilmore [13]. Some TLR sequences were incomplete and they could not be classified into P-type/mcc or V-type/ scc.

\section{Stage specific transcriptome analyses}

In order to assess the expression of TLR genes, we examined publicly available stage-transcriptomic data of various developmental stages for the spiralians $C$. gigas and T. transversa and the ecdysozoans $P$. caudatus and $H$. exemplaris. For $C$. gigas, we examined 19 developmental time-points from early morula to D-shaped larvae, being the transcriptomic data previously published in [104] (accession numbers: SRR334225SRR334243). For T. transversa, 14 stages from oocyte to 2-day juvenile were analyzed, being this dataset available from [123]. For P. caudatus, only 5 embryonic stages (from zigot to late introvertula) were analyzed. The transcriptomic data was obtained from [121]. The $20 \mathrm{H}$. exemplaris embryonic transcriptomes analyzed (from zigot to differentiation) were obtained from [122] (accession numbers: SRR1755597, SRR1755601, SRR1755603, SRR1755606, SRR1755610, SRR1755612, SRR1755621, SRR1755623, SRR1755627, SRR1755631, SRR1755637, SRR1755644, SRR1755647, SRR1755650, SRR1755656, SRR1755662, SRR1755666, SRR1755706, SRR1755715, SRR1755719). We first performed quality-trimming on downloaded RNA-seq raw reads using Trimmomatic v.0.38 [156], removing low quality or $\mathrm{N}$ bases (parameter settings: LEADING:20 TRAILING:20 SLIDINGWINDOW:4:20). To estimate the transcript abundancies, quality-trimmed reads were aligned to reference transcriptome assemblies (C. gigas [104], $T$. transversa and P. caudatus [100], H. exemplaris [112]). We applied two quantification methods: an alignmentbased method using Bowtie2 [157] and RSEM [124], and the ultra-fast alignment-free method kallisto [125]. Both methods reported normalized expression values in transcripts per million (TPM), and we further executed cross-sample normalization among different developmental-stage samples by TMM method [158]. To define a criterion for gene expression value in this study, we performed in situ hybridization of selected TLR genes at different developmental stages in Terebratalia, as well as examining expression values in our analysis corresponding to in situ hybridization data of Hox genes in Terebratalia [123] and Wnt genes in Priapulus [121]. We considered expression for values $\geq 0.15$.

\section{Animal collection and embryonic cultures}

Adult T. transversa specimens were collected in Friday Harbor, USA. The eggs were fertilized, and animals were fixed for WMISH at different developmental stages with $4 \%$ paraformaldehyde for $1 \mathrm{~h}$ at room temperature, as described elsewhere [123, 159]. Next, the samples were repeatedly washed in Ptw and stored in $100 \%$ methanol. 


\section{Gene cloning, probe synthesis, in situ hybridization and imaging}

Specific primers for T. transversa TLRs were designed using the MacVector 10.6.0 software [160]. TLRs were amplified and inserted into pGEM-T Easy vectors (Promega, USA) and transformed in competent $E$. coli cells. Minipreps were prepared using NucleoSpin ${ }^{\circledR}$ Plasmid kit (Macherey-Nagel) and sequenced in the Sequencing facility of the University of Bergen. RNA probes were transcribed using digoxigenin-11-UTP (Roche, USA) with the MEGAscript ${ }^{\mathrm{TM}}$ kit (Invitrogen, Thermo Fisher). Whole mount in situ hybridization (WMISH) was performed as described in [123, 161]. Probes were hybridized at a concentration of $1 \mathrm{ng} / \mu \mathrm{l}$ at $67^{\circ} \mathrm{C}$ during $72 \mathrm{~h}$. Next, they were detected with anti-digoxigeninAP antibody [1:5000] (Roche) and developed using NBT/BCIP (Roche). Samples were washed twice in $100 \%$ ethanol and re-hydrated in descending ethanol steps (75\%, 50\% and 25\% ethanol in PBS). Samples were mounted in $70 \%$ glycerol. Samples were imaged using Axiocam HRc camera connected to an Axioscope Ax10 (Zeiss, Oberkochen, Germany). Images were analyzed using Fiji and Adobe Photoshop CS6.

\section{RNAse treatment}

Specimens stored in methanol were rehydrated in ascending concentration Ptw washes and incubated in $1 \mathrm{mg} / \mathrm{ml}$ of RNAse A (Purelink RNAse A, Invitrogen, \#12091-021) in Ptw for $1 \mathrm{~h}$ at $37^{\circ} \mathrm{C}$. Next, the specimens were then repeatedly washed in $\mathrm{PTw}, \mathrm{mqH} 20$, and in $\mathrm{MeOH}$; and stored at $-20^{\circ} \mathrm{C}$. WMISH was performed as described above.

\section{Illustrations}

Figure plates and illustrations were made with Adobe Illustrator CS6.

\footnotetext{
Abbreviations

AMPs: Antimicrobial peptides; BCIP: 5-Bromo-4-chloro-3-indolyl phosphate; BIC: Bayesian Information Criterion; BUSCO: Benchmarking Universal Single-Copy Orthologs; IL-1: Interleukin-I receptor; LRR: Leucine-rich repeat; LRRCT: Leucine-rich repeat C-terminal domain; LRRNT: Leucine-rich repeat N-terminal domain; Mcc: Multiple cysteine cluster; NBT: Nitro blue tetrazolium; NOD: Nucleotide oligomerization domain; PBS: Phosphate-Buffered Saline; P-type: Protostome type; PTw: PBS with $0.1 \%$ Tween $^{\circledR} 20 ;$ RSEM: RNA-Seq by Expectation Maximization; Scc: Single cysteine cluster; TIR: Toll/IL-1 receptor; TLR: Toll-like receptor; TLR-Ca: Clade a type TLR gene; TLR-C $\beta$ : Clade $\beta$ type TLR gene; TLR-CY: Clade $\gamma$ type TLR gene; TLR-C $\beta / \gamma$ : Proto-TLR gene of clades $\beta$ and $\gamma_{i}$ TLR-like: Toll-like receptor-like; TM: Transmembrane; TMM: Trimmed mean of $M$ values; TPM: Transcripts per million; V-type: Vertebrate type; WMISH: Whole mount in situ hybridization.
}

\section{Supplementary Information}

The online version contains supplementary material available at https://doi. org/10.1186/s12862-021-01927-1.

Additional file 1: Table S1. Sequences included in the phylogenetic analysis.

Additional file 2: Fig. S1. Phylogenetic analysis alignment. Regions rich in gaps located in the positions 150-220 for TLRs not belonging to the three main clades are marked in magenta. In cyan, we mark the positions 349-354 characteristic from clades $\beta$ and $\gamma$; and the gaps corresponding for these positions for the TLRs belonging to clade $a$.

Additional file 3: Fig. S2. Second phylogenetic analysis, excluding the 150-200 aminoacid region. Parameters applied for the construction of this phylogenetic tree are the same than the ones applied for the main phylogenetic analysis (Fig. 4A). Bootstrap values are indicated next to the main nodes and all nodes with bootstrap values $>60$ are marked with full black dots.

Additional file 4: Table S2. Species included in our study.

Additional file 5: Fig. S3. Third phylogenetic analysis, excluding the 349-354 aminoacid region. Parameters applied for the construction of this phylogenetic tree are the same than the ones applied for the main phylogenetic analysis (Fig. 4A). Recovered clades are named $\alpha, \beta$ and $\gamma$. Comparison with the main phylogenetic analysis is represented with blue and magenta dots. Bootstrap values are indicated next to the main nodes and all nodes with bootstrap values $>60$ are marked with full black dots.

Additional file 6: Table S3. Hypsibius exemplaris stage specific transcriptome analyses (RSEM and Kallisto methods).

Additional file 7: Table S4. Priapulus caudatus stage specific transcriptome analyses. Analyses for the different methods (RSEM and Kallisto) and replicates (Rep 1_and Rep_2). For each method, average and standard error (SE) of the two replicates is provided.

Additional file 8: Table S5. Crassostrea gigas stage specific transcriptome analyses (RSEM and Kallisto methods).

Additional file 9: Table S6. Terebratalia transversa stage specific transcriptome analyses. Analyses for the different methods (RSEM and Kallisto) and replicates (Rep 1_and Rep_2). For each method, average and standard error (SE) of the two replicates is provided.

Additional file 10: Fig. S4. RNAse treatment experiment followed by in situ hybridization for the Ttr-TLRa4 gene. A. RNAse treated animals only show the ring-shaped staining (white asterisk). B. Control animals show expression of the Ttr-TLRa4 gene in the brain and the pedicle (blue arrows) and the ring-shaped staining (white asterisk). Therefore, as the ringshaped staining is present in RNAse treated specimens, we conclude that it is nonspecific staining.

Additional file 11: Fig. S5. Different scenarios for TLR evolution. Our phylogenetic analysis suggests different hypothesis about when the duplications that originated the ancestral genes for clades $a, \beta$ and $\gamma$ occurred. First, we can hypothesize that in the planulozoan common ancestor there were present either one (TLR-C $/ \beta / \gamma)$-hypothesis $1 \mathrm{~A}$ - (panels $\mathrm{A}, \mathrm{C}$ and $\mathrm{E}$ ) or two TLRs - hypothesis $1 \mathrm{~B}$ - (panels B, D and F). Second, the duplication of $T L R-C \beta / \gamma$ that gave raise to $T L R-C \beta$ and $T L R-C Y$ could have occurred either in the nephrozoan common ancestor-hypothesis 2A-(panels $A$ and $B$ ), the spiralian common ancestor - hypothesis $2 B$ - (panels $C$ and D) or the trochozoan common ancestor-hypothesis $2 \mathrm{C}$ - (panels $\mathrm{E}$ and F). The panels in this figure show the different combinations of these hypotheses.

\section{Acknowledgements}

We want to thank Daniel Thiel for instructing AOA in performing genome/ transcriptome surveys and phylogenetic analysis and for discussions. We also thank Ferenc Kagan for providing the BUSCO values for the transcriptomes; Ludwik Gasiorowski for discussions; Carmen Andrikou for reading the manuscript and discussions; and Timothy Lynagh for critically reading the manuscript. Furthermore, we would like to thank other former and present 
members from the Hejnol lab for collecting and fixing the T. transversa specimens. We want to further thanks Nadezhda Rimskaya-Korsakova for collecting and providing Galathowenia. Moreover, we want to thank to the two anonymous reviewers that helped to improve the manuscript.

\section{Authors' contributions}

AH designed the study. AOA performed the genome and transcriptome surveys, the phylogenetic analyses, the stage-specific data interpretation, the in situ hybridization, and wrote a draft manuscript. TML performed the transcriptome stage-specific analysis. $A O$ and $A B$ conducted image analyses. $A B$ performed the RNAse experiments. $A H, T M L$ and $A O A$ discussed the data and revised and contributed to the writing. All authors read and approved the manuscript.

\section{Funding}

This study was funded by the European Research Council Community's Framework Program Horizon 2020 (2014-2020) ERC grant Agreement 648861 to $\mathrm{AH}$.

\section{Availability of data and materials}

The datasets supporting the conclusions of this article are included within the article and its additional files.TLR and MyD88 sequences obtained in the genomic/transcriptomic surveys and used in the phylogenetic analyses are available in Additional file 1: Table S1. Terebratalia transversa TLR sequences for which in situ hybridization were performed, have been diposited in NCBI database with the following accession numbers: Ttr-TLRa2: OL353900, Ttr-TLRa3: OL353901, Ttr-TLRa4: OL353902, Ttr-TLRa5: OL353903, Ttr-TLRß3: OL353904, Ttr-TLRY4: OL353905, Ttr-TLRS: OL353906].

\section{Declarations}

Ethics approval and consent to participate Not applicable.

\section{Consent for publication}

Not applicable.

\section{Competing interests}

The authors declare that they have no competing interests.

\section{Author details}

${ }^{1}$ Present Address: Sars International Centre for Marine Molecular Biology, University of Bergen, Thormøhlensgate 55, 5006 Bergen, Norway. ${ }^{2}$ Department of Biological Sciences, University of Bergen, Bergen, Norway. ${ }^{3}$ Present Address: Institute of Cellular and Organismic Biology, Academia Sinica, Taipei, Taiwan.

Received: 2 February 2021 Accepted: 21 October 2021

Published online: 22 November 2021

\section{References}

1. Aderem A, Ulevitch RJ. Toll-like receptors in the induction of the innate immune response. Nature. 2000;406:782-7. https://doi.org/10.1038/ 35021228.

2. Anthoney N, Foldi I, Hidalgo A. Toll and Toll-like receptor signalling in development. Development. 2018;145:1-6. https://doi.org/10.1242/ dev.156018.

3. Barak B, Feldman N, Okun E. Toll-like receptors as developmental tools that regulate neurogenesis during development: an update. Front Neurosci. 2014;8:1-6. https://doi.org/10.3389/fnins.2014.00272.

4. Imler J-L, Hoffmann JA. Toll receptors in innate immunity. Trends Cell Biol. 2001;11:304-11. https://doi.org/10.1016/S0962-8924(01)02004-9.

5. Kawai T, Akira S. The role of pattern-recognition receptors in innate immunity: update on Toll-like receptors. Nat Immunol. 2010;11:373-84. https://doi.org/10.1038/ni.1863.

6. Medzhitov R. Toll like receptors and innate immunity. Nat Rev. 2001;1:135-45.
7. Leulier F, Lemaitre B. Toll-like receptors-taking an evolutionary approach. Nat Rev Genet. 2008;9:165-78. https://doi.org/10.1038/nrg23 03.

8. Anderson KV, Jürgens $G$, Nüsslein-Volhard C. Establishment of dorsalventral polarity in the Drosophila embryo: genetic studies on the role of the Toll gene product. Cell. 1985;42:779-89. https://doi.org/10.1016/ 0092-8674(85)90274-0.

9. Anderson KV, Nüsslein-Volhard C. Information for the dorsal-ventral pattern of the Drosophila embryo is stored as maternal mRNA. Nature. 1984;311:223-7. https://doi.org/10.1038/311223a0.

10. Lemaitre B, Nicolas E, Michaut L, Reichhart J-M, Hoffmann JA. The dorsoventral regulatory gene cassette Spätzle/Toll/Cactus controls the potent antifungal response in Drosophila adults. Cell. 1996;86:973-83. https://doi.org/10.1016/S0092-8674(00)80172-5.

11. Medzhitov R, Preston-Hurlburt P, Janeway CA. A human homologue of the Drosophila Toll protein signals activation of adaptive immunity. Nature. 1997;388:394-7. https://doi.org/10.1038/41131.

12. Coscia M, Giacomelli S, Oreste U. Toll-like receptors: an overview from invertebrates to vertebrates. Invertebr Surviv J. 2011;8:210-26.

13. Brennan JJ, Gilmore TD. Evolutionary origins of Toll-like receptor signaling. Mol Biol Evol. 2018;35:1576-87. https://doi.org/10.1093/molbev/ msy050.

14. Nie L, Cai S-Y, Shao J-Z, Chen J. Toll-like receptors, associated biological roles, and signaling networks in non-mammals. Front Immunol. 2018;9:1-19. https://doi.org/10.3389/fimmu.2018.01523.

15. Gay NJ, Gangloff M. Structure and function of Toll receptors and their ligands. Annu Rev Biochem. 2007;76:141-65. https://doi.org/10.1146/ annurev.biochem.76.060305.151318.

16. Barton GM. Toll-like receptor signaling pathways. Science. 2003;300:1524-5. https://doi.org/10.1126/science.1085536.

17. Valanne S, Wang J-H, Rämet M. The Drosophila Toll signaling pathway. J Immunol. 2011;186:649-56. https://doi.org/10.4049/jimmunol.1002302.

18. Tauszig S, Jouanguy E, Hoffmann JA, Imler J-L. Toll-related receptors and the control of antimicrobial peptide expression in Drosophila. Proc Natl Acad Sci. 2000;97:10520-5. https://doi.org/10.1073/pnas.180130797.

19. Lemaitre B, Reichhart J-M, Hoffmann JA. Drosophila host defense: differential induction of antimicrobial peptide genes after infection by various classes of microorganisms. Proc Natl Acad Sci. 1997;94:14614-9. https://doi.org/10.1073/pnas.94.26.14614.

20. Leulier F, Parquet C, Pili-Floury S, Ryu J-H, Caroff M, Lee W-J, et al. The Drosophila immune system detects bacteria through specific peptidoglycan recognition. Nat Immunol. 2003;4:478-84. https://doi.org/10. 1038/ni922

21. Chowdhury M, Li C-F, He Z, Lu Y, Liu X-S, Wang Y-F, et al. Toll family members bind multiple Spätzle proteins and activate antimicrobial peptide gene expression in Drosophila. J Biol Chem. 2019;294:1017281. https://doi.org/10.1074/jbc.RA118.006804.

22. Pasare C, Medzhitov R. Toll-like receptors: linking innate and adaptive immunity. In: Gupta S, Paul WE, Steinman R, editors. Mechanisms of lymphocyte activation and immune regulation X. Boston: Springer US; 2005. p. 11-8. https://doi.org/10.1007/0-387-24180-9 2.

23. Portou MJ, Baker D, Abraham D, Tsui J. The innate immune system, Tolllike receptors and dermal wound healing: a review. Vascul Pharmacol. 2015;71:31-6. https://doi.org/10.1016/j.vph.2015.02.007.

24. Lester SN, Li K. Toll-like receptors in antiviral innate immunity. J Mol Biol. 2014;426:1246-64. https://doi.org/10.1016/j.jmb.2013.11.024.

25. Akira S, Uematsu S, Takeuchi O. Pathogen recognition and innate immunity. Cell. 2006;124:783-801. https://doi.org/10.1016/j.cell.2006.02 015.

26. Manicassamy S, Pulendran B. Modulation of adaptive immunity with Toll-like receptors. Semin Immunol. 2009;21:185-93. https://doi.org/10. 1016/j.smim.2009.05.005.

27. Brennan JJ, Messerschmidt JL, Williams LM, Matthews BJ, Reynoso M, Gilmore TD. Sea anemone model has a single Toll-like receptor that can function in pathogen detection, NF-KB signal transduction, and development. Proc Natl Acad Sci. 2017;114:E10122-31. https://doi.org/ 10.1073/pnas.1711530114.

28. Ren Y, Ding D, Pan B, Bu W. The TLR13-MyD88-NF-kB signalling pathway of Cyclina sinensis plays vital roles in innate immune responses. Fish Shellfish Immunol. 2017;70:720-30. https://doi.org/10.1016/j.fsi.2017.09. 060. 
29. Wang K, del Castillo C, Corre E, Pales Espinosa E, Allam B. Clam focal and systemic immune responses to QPX infection revealed by RNA-seq technology. BMC Genomics. 2016;17:146. https://doi.org/10.1186/ s12864-016-2493-9.

30. Zhang Y, He X, Yu F, Xiang Z, Li J, Thorpe KL, et al. Characteristic and functional analysis of Toll-like Receptors (TLRs) in the lophotrocozoan, Crassostrea gigas, reveals ancient origin of TLR-mediated innate immunity. PLoS ONE. 2013;8: e76464. https://doi.org/10.1371/journal.pone. 0076464.

31. Priyathilaka TT, Bathige SDNK, Lee S, Nam B-H, Lee J. Transcriptomewide identification, functional characterization, and expression analysis of two novel invertebrate-type Toll-like receptors from disk abalone (Haliotis discus discus). Fish Shellfish Immunol. 2019;84:802-15. https:// doi.org/10.1016/j.fsi.2018.10.062.

32. Prochazkova P, Roubalova R, Skanta F, Dvorak J, Pacheco NIN, Kolarik $\mathrm{M}$, et al. Developmental and immune role of a novel multiple cysteine cluster TLR from Eisenia andrei earthworms. Front Immunol. 2019;10:118. https://doi.org/10.3389/fimmu.2019.01277.

33. Škanta F, Roubalová R, Dvořák J, Procházková P, Bilej M. Molecular cloning and expression of TLR in the Eisenia andrei earthworm. Dev Comp Immunol. 2013;41:694-702. https://doi.org/10.1016/j.dci.2013.08.009.

34. Li X-C, Zhu L, Li L-G, Ren Q, Huang Y-Q, Lu J-X, et al. A novel myeloid differentiation factor 88 homolog, SpMyD88, exhibiting SpToll-binding activity in the mud crab Scylla paramamosain. Dev Comp Immunol. 2013;39:313-22. https://doi.org/10.1016/j.dci.2012.11.011.

35. Russo R, Chiaramonte M, Matranga V, Arizza V. A member of the T/r family is involved in dsRNA innate immune response in Paracentrotus lividus sea urchin. Dev Comp Immunol. 2015;51:271-7. https://doi.org/ 10.1016/j.dci.2015.04.007.

36. Eldon E, Kooyer S, D'Evelyn D, Duman M, Lawinger P, Botas J, et al. The Drosophila 18 wheeler is required for morphogenesis and has striking similarities to Toll. Development. 1994;120:885-99.

37. Benton MA, Pechmann M, Frey N, Stappert D, Conrads KH, Chen Y-T, et al. Toll genes have an ancestral role in axis elongation. Curr Biol. 2016;26:1609-15. https://doi.org/10.1016/j.cub.2016.04.055.

38. Halfon MS, Hashimoto C, Keshishian H. The Drosophila Toll gene functions zygotically and its necessary for proper motoneuron and muscle development. Dev Biol. 1995;169:151-67. https://doi.org/10.1006/dbio. 1995.1134.

39. Ward A, Hong W, Favaloro V, Luo L. Toll receptors instruct axon and dendrite targeting and participate in synaptic partner matching in a Drosophila olfactory circuit. Neuron. 2015;85:1013-28. https://doi.org/ 10.1016/j.neuron.2015.02.003.

40. Byun PK, Zhang C, Yao B, Wardwell-Ozgo J, Terry D, Jin P, et al. The Taiman transcriptional coactivator engages Toll signals to promote apoptosis and intertissue invasion in Drosophila. Curr Biol. 2019;29:2790-800. https://doi.org/10.1016/j.cub.2019.07.012.

41. Meyer SN, Amoyel M, Bergantiños C, de la Cova C, Schertel C, Basler K, et al. An ancient defense system eliminates unfit cells from developing tissues during cell competition. Science. 2014;346:1258236. https://doi. org/10.1126/science.1258236.

42. Wang J, Tao Y, Reim I, Gajewski K, Frasch M, Schulz RA. Expression, regulation, and requirement of the Toll transmembrane protein during dorsal vessel formation in Drosophila melanogaster. Mol Cell Biol. 2005;25:4200-10. https://doi.org/10.1128/MCB.25.10.4200-4210.2005.

43. Janssen R, Lionel L. Embryonic expression of a Long Toll (Loto) gene in the onychophorans Euperipatoides kanangrensis and Cephalofovea clandestina. Dev Genes Evol. 2018;228:171-8. https://doi.org/10.1007/ s00427-018-0609-8.

44. Rolls A, Shechter R, London A, Ziv Y, Ronen A, Levy R, et al. Toll-like receptors modulate adult hippocampal neurogenesis. Nat Cell Biol. 2007;9:1081-8. https://doi.org/10.1038/ncb1629.

45. Shechter R, Ronen A, Rolls A, London A, Bakalash S, Young MJ, et al. Tolllike receptor 4 restricts retinal progenitor cell proliferation. J Cell Biol. 2008;183:393-400. https://doi.org/10.1083/jcb.200804010.

46. Hung Y-F, Chen C-Y, Shih Y-C, Liu H-Y, Huang C-M, Hsueh Y-P. Endosomal TLR3, TLR7, and TLR8 control neuronal morphology through different transcriptional programs. J Cell Biol. 2018;217:2727-42. https://doi.org/ 10.1083/jcb.201712113.
47. Kaul D, Habbel P, Derkow K, Krüger C, Franzoni E, Wulczyn FG, et al. Expression of Toll-Like Receptors in the developing brain. PLOS ONE. 2012;7: e37767. https://doi.org/10.1371/journal.pone.0037767.

48. Hashimoto C, Hudson KL, Anderson KV. The Toll gene of Drosophila, required for dorsal-ventral embryonic polarity, appears to encode a transmembrane protein. Cell. 1988;52:269-79. https://doi.org/10.1016/ 0092-8674(88)90516-8.

49. Schneider DS, Hudson KL, Lin TY, Anderson KV. Dominant and recessive mutations define functional domains of Toll, a transmembrane protein required for dorsal-ventral polarity in the Drosophila embryo. Genes Dev. 1991;5:797-807. https://doi.org/10.1101/gad.5.5.797.

50. Bell JK, Mullen GED, Leifer CA, Mazzoni A, Davies DR, Segal DM. Leucinerich repeats and pathogen recognition in Toll-like receptors. Trends Immunol. 2003;24:528-33. https://doi.org/10.1016/S1471-4906(03) 00242-4.

51. Kobe B, Kajava AV. The leucine-rich repeat as a protein recognition motif. Curr Opin Struct Biol. 2001;11:725-32. https://doi.org/10.1016/ S0959-440X(01)00266-4.

52. Rock FL, Hardiman G, Timans JC, Kastelein RA, Bazan JF. A family of human receptors structurally related to Drosophila Toll. Proc Natl Acad Sci. 1998:95:588-93. https://doi.org/10.1073/pnas.95.2.588.

53. Dolan J, Walshe K, Alsbury S, Hokamp K, O'Keeffe S, Okafuji T, et al. The extracellular Leucine-Rich Repeat superfamily; a comparative survey and analysis of evolutionary relationships and expression patterns. BMC Genomics. 2007;8:320. https://doi.org/10.1186/1471-2164-8-320.

54. Shaw MH, Reimer T, Kim Y-G, Nuñez G. NOD-like receptors (NLRs): bona fide intracellular microbial sensors. Curr Opin Immunol. 2008;20:377-82. https://doi.org/10.1016/j.coi.2008.06.001.

55. Milán M, Weihe U, Pérez L, Cohen SM. The LRR proteins Capricious and Tartan mediate cell interactions during DV boundary formation in the Drosophila wing. Cell. 2001;106:785-94. https://doi.org/10.1016/S00928674(01)00489-5.

56. de Wit J, Hong W, Luo L, Ghosh A. Role of Leucine-Rich Repeat proteins in the development and function of neural circuits. Annu Rev Cell Dev Biol. 2011;27:697-729. https://doi.org/10.1146/annurev-cellb io-092910-154111.

57. Burch-Smith TM, Dinesh-Kumar SP. The functions of plant TIR domains. Science's STKE Signal Trans Knowl Environ. 2007;2007:1-4. https://doi. org/10.1126/stke.4012007pe46.

58. Gao Y, Wang W, Zhang T, Gong Z, Zhao H, Han G-Z. Out of water: the origin and early diversification of plant $R$-Genes. Plant Physiol. 2018:177:82-9. https://doi.org/10.1104/pp.18.00185.

59. Gay N, Keith F. Drosophila Toll and IL-1 receptor. Nature. 1991;351:355-6. https://doi.org/10.1038/351355b0.

60. Bonnert TP, Garka KE, Parnet P, Sonoda G, Testa JR, Sims JE. The cloning and characterization of human MyD88: a member of an IL-1 receptor related family. FEBS Lett. 1997;402:81-4. https://doi.org/10.1016/S00145793(96)01506-2.

61. Horng T, Medzhitov R. Drosophila MyD88 is an adapter in the Toll signaling pathway. Proc Natl Acad Sci. 2001;98:12654-8. https://doi.org/10. 1073/pnas.231471798.

62. Medzhitov R, Preston-Hurlburt P, Kopp E, Stadlen A, Chen C, Ghosh $\mathrm{S}$, et al. MyD88 Is an adaptor protein in the $\mathrm{hToll} / \mathrm{LL}-1$ receptor family signaling pathways. Mol Cell. 1998;2:253-8. https://doi.org/10.1016/ S1097-2765(00)80136-7.

63. Imler J-L, Zheng L. Biology of Toll receptors: lessons from insects and mammals. J Leukoc Biol. 2004;75:18-26. https://doi.org/10.1189/jlb. 0403160.

64. Hibino T, Loza-Coll M, Messier C, Majeske AJ, Cohen AH, Terwilliger DP et al. The immune gene repertoire encoded in the purple sea urchin genome. Dev Biol. 2006;300:349-65. https://doi.org/10.1016/j.ydbio. 2006.08.065.

65. Davidson CR, Best NM, Francis JW, Cooper EL, Wood TC. Toll-like receptor genes (TLRs) from Capitella capitata and Helobdella robusta (Annelida). Dev Comp Immunol. 2008;32:608-12. https://doi.org/10.1016/j.dci. 2007.11.004.

66. Halanych KM, Kocot KM. Repurposed transcriptomic data facilitate discovery of innate immunity Toll-Like Receptor (TLR) genes across Lophotrochozoa. Biol Bull. 2014;227:201-9. https://doi.org/10.1086/ BBLV227n2p201. 
67. Liu G, Zhang H, Zhao C, Zhang H. Evolutionary history of the TollLike Receptor gene family across vertebrates. Genome Biol Evol. 2020;12:3615-34. https://doi.org/10.1093/gbe/evz266.

68. Richter DJ, Fozouni P, Eisen MB, King N. Gene family innovation, conservation and loss on the animal stem lineage. elife. 2018;7:1-43. https://doi.org/10.7554/eLife.34226.

69. Gauthier MEA, Du Pasquier L, Degnan BM. The genome of the sponge Amphimedon queenslandica provides new perspectives into the origin of Toll-like and interleukin 1 receptor pathways. Evol Dev. 2010;12:519-33. https://doi.org/10.1111/j.1525-142X.2010.00436.x.

70. Flot J-F, Hespeels B, Li X, Noel B, Arkhipova I, Danchin EGJ, et al. Genomic evidence for ameiotic evolution in the bdelloid rotifer Adineta vaga. Nature. 2013;500:453-7. https://doi.org/10.1038/natur e12326.

71. Peiris TH, Hoyer KK, Oviedo NJ. Innate immune system and tissue regeneration in planarians: an area ripe for exploration. Semin Immunol. 2014;26:295-302. https://doi.org/10.1016/j.smim.2014.06.005.

72. Poole AZ, Weis VM. TIR-domain-containing protein repertoire of nine anthozoan species reveals coral-specific expansions and uncharacterized proteins. Dev Comp Immunol. 2014;46:480-8. https://doi.org/ 10.1016/j.dci.2014.06.002.

73. Kamm K, Schierwater B, DeSalle R. Innate immunity in the simplest animals_placozoans. BMC Genomics. 2019;20:1-12. https://doi.org/ 10.1186/s12864-018-5377-3.

74. Wiens M, Korzhev M, Perovic-Ottstadt S, Luthringer B, Brandt D, Klein $\mathrm{S}$, et al. Toll-like receptors are part of the innate immune defense system of sponges (Demospongiae: Porifera). Mol Biol Evol. 2006;24:792-804. https://doi.org/10.1093/molbev/msl208.

75. Bosch TCG, Augustin R, Anton-Erxleben F, Fraune S, Hemmrich G, Zill $\mathrm{H}$, et al. Uncovering the evolutionary history of innate immunity: the simple metazoan Hydra uses epithelial cells for host defence. Dev Comp Immunol. 2009;33:559-69. https://doi.org/10.1016/j.dci.2008. 10.004 .

76. Franzenburg S, Fraune S, Kunzel S, Baines JF, Domazet-Loso T, Bosch TCG. MyD88-deficient Hydra reveal an ancient function of TLR signaling in sensing bacterial colonizers. Proc Natl Acad Sci. 2012;109:19374-9. https://doi.org/10.1073/pnas.1213110109.

77. Jault C, Pichon L, Chluba J. Toll-like receptor gene family and TIRdomain adapters in Danio rerio. Mol Immunol. 2004;40:759-71. https:// doi.org/10.1016/j.molimm.2003.10.001

78. Yilmaz A, Shen S, Adelson DL, Xavier S, Zhu JJ. Identification and sequence analysis of chicken Toll-like receptors. Immunogenetics. 2005;56:743-53. https://doi.org/10.1007/s00251-004-0740-8.

79. Ishii A, Kawasaki M, Matsumoto M, Tochinai S, Seya T. Phylogenetic and expression analysis of amphibian Xenopus Toll-like receptors. Immunogenetics. 2007;59:281-93. https://doi.org/10.1007/s00251-007-0193-y.

80. Inamori K, Ariki S, Kawabata S. A Toll-like receptor in horseshoe crabs. Immunol Rev. 2004;198:106-15. https://doi.org/10.1111/j.0105-2896. 2004.0131.x.

81. Palmer WJ, Jiggins FM. Comparative genomics reveals the origins and diversity of arthropod immune systems. Mol Biol Evol. 2015;32:2111-29. https://doi.org/10.1093/molbev/msv093.

82. Pujol N, Link EM, Liu LX, Kurz CL, Alloing G, Tan M-W, et al. A reverse genetic analysis of components of the Toll signaling pathway in Caenorhabditis elegans. Curr Biol. 2001;11:809-21. https://doi.org/10.1016/ S0960-9822(01)00241-X.

83. Williams LM, Fuess LE, Brennan JJ, Mansfield KM, Salas-Rodriguez E, Welsh J, et al. A conserved Toll-like receptor-to-NF-KB signaling pathway in the endangered coral Orbicella faveolata. Dev Comp Immunol. 2018;79:128-36. https://doi.org/10.1016/j.dci.2017.10.016.

84. Leclère L, Horin C, Chevalier S, Lapébie P, Dru P, Peron S, et al. The genome of the jellyfish Clytia hemisphaerica and the evolution of the cnidarian life-cycle. Nat Ecol Evol. 2019;3:801-10. https://doi.org/10. 1038/s41559-019-0833-2.

85. Traylor-Knowles N, Vandepas LE, Browne WE. Still enigmatic: innate immunity in the ctenophore Mnemiopsis leidyi. Integr Comp Biol. 2019;59:811-8. https://doi.org/10.1093/icb/icz116.

86. Moroz LL, Kocot KM, Citarella MR, Dosung S, Norekian TP, Povolotskaya IS, et al. The ctenophore genome and the evolutionary origins of neural systems. Nature. 2014;510:109-14. https://doi.org/10.1038/natur e13400.
87. Adema CM, Hillier LW, Jones CS, Loker ES, Knight M, Minx P, et al. Whole genome analysis of a schistosomiasis-transmitting freshwater snail. Nat Commun. 2017;8:15451. https://doi.org/10.1038/ncomms15451.

88. Ren Y, Pan H, Pan B, Bu W. Identification and functional characterization of three TLR signaling pathway genes in Cyclina sinensis. Fish Shellfish Immunol. 2016;50:150-9. https://doi.org/10.1016/j.fsi.2016.01.025.

89. Luo Y-J, Kanda M, Koyanagi R, Hisata K, Akiyama T, Sakamoto H, et al. Nemertean and phoronid genomes reveal lophotrochozoan evolution and the origin of bilaterian heads. Nat Ecol Evol. 2018;2:141-51. https:// doi.org/10.1038/s41559-017-0389-y.

90. Cuvillier-Hot V, Boidin-Wichlacz C, Slomianny C, Salzet M, Tasiemski A. Characterization and immune function of two intracellular sensors, HmTLR1 and HmNLR, in the injured CNS of an invertebrate. Dev Comp Immunol. 2011;35:214-26. https://doi.org/10.1016/j.dci.2010.09.011.

91. Peng J, Li Q, Xu L, Wei P, He P, Zhang X, et al. Chromosome-level analysis of the Crassostrea hongkongensis genome reveals extensive duplication of immune-related genes in bivalves. Mol Ecol Resour. 2020;20:980-94. https://doi.org/10.1111/1755-0998.13157.

92. Zheng L, Zhang L, Lin H, McIntosh MT, Malacrida AR. Toll-like receptors in invertebrate innate immunity. Invertebr Surviv J. 2005;2:105-13.

93. Mapalo MA, Arakawa K, Baker CM, Persson DK, Mirano-Bascos $D$, Giribet $G$. The unique antimicrobial recognition and signaling pathways in tardigrades with a comparison across Ecdysozoa. G3 Genes|Genomes|Genetics. 2020;10:1137-48. https://doi.org/10.1534/ g3.119.400734

94. Ji J, Ramos-Vicente D, Navas-Pérez E, Herrera-Úbeda C, Lizcano JM, Garcia-Fernàndez J, et al. Characterization of the TLR family in Branchiostoma lanceolatum and discovery of a novel TLR22-like involved in dsRNA recognition in amphioxus. Front Immunol. 2018;9:1-15. https:// doi.org/10.3389/fimmu.2018.02525.

95. Tassia MG, Whelan NV, Halanych KM. Toll-like receptor pathway evolution in deuterostomes. Proc Natl Acad Sci. 2017;114:7055-60. https:// doi.org/10.1073/pnas.1617722114.

96. Denoeud F, Henriet S, Mungpakdee S, Aury J-M, Da Silva C, Brinkmann $\mathrm{H}$, et al. Plasticity of animal genome architecture unmasked by rapid evolution of a pelagic tunicate. Science. 2010;330:1381-5. https://doi. org/10.1126/science.1194167.

97. Sasaki N, Ogasawara M, Sekiguchi T, Kusumoto S, Satake H. Tolllike Receptors of the ascidian Ciona intestinalis. J Biol Chem. 2009:284:27336-43. https://doi.org/10.1074/jbc.M109.032433.

98. Dunn CW, Giribet G, Edgecombe GD, Hejnol A. Animal phylogeny and its evolutionary implications. Annu Rev Ecol Evol Syst. 2014;45:371-95. https://doi.org/10.1146/annurev-ecolsys-120213-091627.

99. Roach JC, Glusman G, Rowen L, Kaur A, Purcell MK, Smith KD, et al. The evolution of vertebrate Toll-like receptors. Proc Natl Acad Sci. 2005;102:9577-82. https://doi.org/10.1073/pnas.0502272102.

100. Cannon JT, Vellutini BC, Smith J, Ronquist F, Jondelius U, Hejnol A. Xenacoelomorpha is the sister group to Nephrozoa. Nature. 2016;530:89-93. https://doi.org/10.1038/nature16520.

101. Wong YH, Ryu T, Seridi L, Ghosheh Y, Bougouffa S, Qian P-Y, et al. Transcriptome analysis elucidates key developmental components of bryozoan lophophore development. Sci Rep. 2015;4:6534. https://doi. org/10.1038/srep06534

102. Neves RC, Guimaraes JC, Strempel S, Reichert H. Transcriptome profiling of Symbion pandora (phylum Cycliophora): insights from a differential gene expression analysis. Org Divers Evol. 2017;17:111-9. https://doi. org/10.1007/s13127-016-0315-1.

103. Simakov O, Marletaz F, Cho S-J, Edsinger-Gonzales E, Havlak P, Hellsten $\mathrm{U}$, et al. Insights into bilaterian evolution from three spiralian genomes. Nature. 2013;493:526-31. https://doi.org/10.1038/nature11696.

104. Zhang G, Fang X, Guo X, Li L, Luo R, Xu F, et al. The oyster genome reveals stress adaptation and complexity of shell formation. Nature. 2012;490:49-54. https://doi.org/10.1038/nature11413.

105. Albertin CB, Simakov O, Mitros T, Wang ZY, Pungor JR, Edsinger-Gonzales $E$, et al. The octopus genome and the evolution of cephalopod neural and morphological novelties. Nature. 2015;524:220-4. https:// doi.org/10.1038/nature14668

106. Luo Y-J, Takeuchi T, Koyanagi R, Yamada L, Kanda M, Khalturina M, et al. The Lingula genome provides insights into brachiopod evolution and the origin of phosphate biomineralization. Nat Commun. 2015;6:1-10. https://doi.org/10.1038/ncomms9301. 
107. Laumer CE, Hejnol A, Giribet G. Nuclear genomic signals of the 'microturbellarian' roots of platyhelminth evolutionary innovation. Elife. 2015;4:1-31. https://doi.org/10.7554/eLife.05503.

108. Struck TH, Wey-Fabrizius AR, Golombek A, Hering L, Weigert A, Bleidorn C, et al. Platyzoan paraphyly based on phylogenomic data supports a noncoelomate ancestry of Spiralia. Mol Biol Evol. 2014;31:1833-49. https://doi.org/10.1093/molbev/msu143.

109. Wasik K, Gurtowski J, Zhou X, Ramos OM, Delás MJ, Battistoni G, et al. Genome and transcriptome of the regeneration-competent flatworm, Macrostomum lignano. Proc Natl Acad Sci. 2015;112:12462-7. https:// doi.org/10.1073/pnas.1516718112.

110. Tsai IJ, Zarowiecki M, Holroyd N, Garciarrubio A, Sanchez-Flores A, Brooks KL, et al. The genomes of four tapeworm species reveal adaptations to parasitism. Nature. 2013;496:57-63. https://doi.org/10.1038/ nature12031.

111. Eyres I, Boschetti C, Crisp A, Smith TP, Fontaneto D, Tunnacliffe A, et al. Horizontal gene transfer in bdelloid rotifers is ancient, ongoing and more frequent in species from desiccating habitats. BMC Biol. 2015;13:1-17. https://doi.org/10.1186/s12915-015-0202-9.

112. Yoshida Y, Koutsovoulos G, Laetsch DR, Stevens L, Kumar S, Horikawa DD, et al. Comparative genomics of the tardigrades Hypsibius dujardini and Ramazzottius varieornatus. PLoS Biol. 2017;15: e2002266. https:// doi.org/10.1371/journal.pbio.2002266.

113. Hashimoto T, Horikawa DD, Saito Y, Kuwahara H, Kozuka-Hata H, Shin-IT, et al. Extremotolerant tardigrade genome and improved radiotolerance of human cultured cells by tardigrade-unique protein. Nat Commun. 2016;7:1-14. https://doi.org/10.1038/ncomms12808.

114. Sharma PP, Kaluziak ST, Pérez-Porro AR, González VL, Hormiga G, Wheeler WC, et al. Phylogenomic interrogation of arachnida reveals systemic conflicts in phylogenetic signal. Mol Biol Evol. 2014;31:2963-84. https://doi.org/10.1093/molbev/msu235.

115. Desjardins CA, Cerqueira GC, Goldberg JM, Dunning Hotopp JC, Haas BJ, Zucker J, et al. Genomics of Loa loa, a Wolbachia-free filarial parasite of humans. Nat Genet. 2013;45:495-500. https://doi.org/10.1038/ng. 2585.

116. Cotton JA, Bennuru S, Grote A, Harsha B, Tracey A, Beech R, et al. The genome of Onchocerca volvulus, agent of river blindness. Nat Microbiol. 2017;2:16216. https://doi.org/10.1038/nmicrobiol.2016.216.

117. Colbourne JK, Pfrender ME, Gilbert D, Thomas WK, Tucker A, Oakley $\mathrm{TH}$, et al. The ecoresponsive genome of Daphnia pulex. Science. 2011;331:555-61. https://doi.org/10.1126/science.1197761.

118. Gulia-Nuss M, Nuss AB, Meyer JM, Sonenshine DE, Roe RM, Waterhouse RM, et al. Genomic insights into the Ixodes scapularis tick vector of Lyme disease. Nat Commun. 2016;7:1-13. https://doi.org/10.1038/ncomm s10507.

119. Kasamatsu J, Oshiumi H, Matsumoto M, Kasahara M, Seya T. Phylogenetic and expression analysis of lamprey Toll-like receptors. Dev Comp Immunol. 2010;34:855-65. https://doi.org/10.1016/j.dci.2010.03.004.

120. Ishii A, Matsuo A, Sawa H, Tsujita T, Shida K, Matsumoto M, et al. Lamprey TLRs with properties distinct from those of the variable lymphocyte receptors. J Immunol. 2007;178:397-406. https://doi.org/10.4049/ jimmunol.178.1.397.

121. Hogvall M, Vellutini BC, Martín-Durán JM, Hejnol A, Budd GE, Janssen R. Embryonic expression of priapulid Wnt genes. Dev Genes Evol. 2019;229:125-35. https://doi.org/10.1007/s00427-019-00636-6.

122. Levin M, Anavy L, Cole AG, Winter E, Mostov N, Khair S, et al. The middevelopmental transition and the evolution of animal body plans. Nature. 2016;531:637-41. https://doi.org/10.1038/nature16994.

123. Schiemann SM, Martín-Durán JM, Børve A, Vellutini BC, Passamaneck YJ, Hejnol A. Clustered brachiopod Hox genes are not expressed collinearly and are associated with lophotrochozoan novelties. Proc Natl Acad Sci. 2017;114:E1913-22. https://doi.org/10.1073/pnas.1614501114.

124. Li B, Dewey CN. RSEM: accurate transcript quantification from RNASeq data with or without a reference genome. BMC Bioinformatics. 2011;12:323. https://doi.org/10.1186/1471-2105-12-323.

125. Bray NL, Pimentel H, Melsted P, Pachter L. Near-optimal probabilistic RNA-seq quantification. Nat Biotechnol. 2016;34:525-7. https://doi.org/ 10.1038/nbt.3519.

126. Stricker SA, Reed CG. The ontogeny of shell secretion in Terebratalia transversa (brachiopoda, articulata) I. Development of the mantle. J Morphol. 1985;183:233-50. https://doi.org/10.1002/jmor.1051830302.
127. Sinigaglia C, Thiel D, Hejnol A, Houliston E, Leclère L. A safer, urea-based in situ hybridization method improves detection of gene expression in diverse animal species. Dev Biol. 2018;434:15-23. https://doi.org/10. 1016/j.ydbio.2017.11.015.

128. Grande C, Martín-Durán JM, Kenny NJ, Truchado-García M, Hejnol A. Evolution, divergence and loss of the Nodal signalling pathway: new data and a synthesis across the Bilateria. Int J Dev Biol. 2014;58:521-32. https://doi.org/10.1387/ijdb.140133cg.

129. Luo C, Zheng L. Independent evolution of Toll and related genes in insects and mammals. Immunogenetics. 2000;51:92-8. https://doi.org/ $10.1007 /$ s002510050017.

130. Luna C, Wang X, Huang Y, Zhang J, Zheng L. Characterization of four Toll related genes during development and immune responses in Anopheles gambiae. Insect Biochem Mol Biol. 2002;32:1171-9. https://doi.org/ 10.1016/S0965-1748(02)00053-X.

131. Marlétaz F, Peijnenburg KTCA, Goto T, Satoh N, Rokhsar DS. A new spiralian phylogeny places the enigmatic arrow worms among gnathiferans. Curr Biol. 2019;29:312-318.e3. https://doi.org/10.1016/j.cub.2018. 11.042.

132. Zhang L, Li L, Guo X, Litman GW, Dishaw LJ, Zhang G. Massive expansion and functional divergence of innate immune genes in a protostome. Sci Rep. 2015;5:8693. https://doi.org/10.1038/srep08693.

133. Guo X, He Y, Zhang L, Lelong C, Jouaux A. Immune and stress responses in oysters with insights on adaptation. Fish Shellfish Immunol. 2015;46:107-19. https://doi.org/10.1016/j.fsi.2015.05.018.

134. Slota LA, Miranda EM, McClay DR. Spatial and temporal patterns of gene expression during neurogenesis in the sea urchin Lytechinus variegatus. EvoDevo. 2019;10:2. https://doi.org/10.1186/ s13227-019-0115-8.

135. Wen X, Fuhrman S, Michaels GS, Carr DB, Smith S, Barker JL, et al. Largescale temporal gene expression mapping of central nervous system development. Proc Natl Acad Sci. 1998;95:334-9. https://doi.org/10. 1073/pnas.95.1.334.

136. Sako K, Pradhan SJ, Barone V, Inglés-Prieto Á, Müller P, Ruprecht V, et al. Optogenetic control of Nodal signaling reveals a temporal pattern of Nodal signaling regulating cell fate specification during gastrulation. Cell Rep. 2016;16:866-77. https://doi.org/10.1016/j.celrep.2016.06.036.

137. Hamdoun A, Epel D. Embryo stability and vulnerability in an always changing world. Proc Natl Acad Sci USA. 2007;104:1745-50. https://doi. org/10.1073/pnas.0610108104.

138. Benkendorff K, Davis AR, Bremner JB. Chemical defense in the egg masses of benthic invertebrates: an assessment of antibacterial activity in 39 mollusks and 4 polychaetes. J Invertebr Pathol. 2001;78:109-18. https://doi.org/10.1006/jipa.2001.5047.

139. Balbi T, Auguste M, Cortese K, Montagna M, Borello A, Pruzzo C, et al. Responses of Mytilus galloprovincialis to challenge with the emerging marine pathogen Vibrio coralliilyticus. Fish Shellfish Immunol. 2019;84:352-60. https://doi.org/10.1016/j.fsi.2018.10.011.

140. Deris ZM, lehata S, Ikhwanuddin M, Sahimi MBMK, Dinh Do T, Sorgeloos $P$, et al. Immune and bacterial toxin genes expression in different giant tiger prawn, Penaeus monodon post-larvae stages following AHPNDcausing strain of Vibrio parahaemolyticus challenge. Aquacult Rep. 2020;16: 100248. https://doi.org/10.1016/j.aqrep.2019.100248.

141. Tirapé A, Bacque C, Brizard R, Vandenbulcke F, Boulo V. Expression of immune-related genes in the oyster Crassostrea gigas during ontogenesis. Dev Comp Immunol. 2007;31:859-73. https://doi.org/10.1016/j.dci. 2007.01.005.

142. Yuan S, Huang S, Zhang W, Wu T, Dong M, Yu Y, et al. An amphioxus TLR with dynamic embryonic expression pattern responses to pathogens and activates NF-KB pathway via MyD88. Mol Immunol. 2009;46:234856. https://doi.org/10.1016/j.molimm.2009.03.022.

143. Balseiro P, Moreira R, Chamorro R, Figueras A, Novoa B. Immune responses during the larval stages of Mytilus galloprovincialis: metamorphosis alters immunocompetence, body shape and behavior. Fish Shellfish Immunol. 2013;35:438-47. https://doi.org/10.1016/j.fsi.2013.04. 044.

144. Shah M, Brown KM, Smith LC. The gene encoding the sea urchin complement protein, $\mathrm{SpC} 3$, is expressed in embryos and can be upregulated by bacteria. Dev Comp Immunol. 2003;27:529-38. https://doi.org/ 10.1016/S0145-305X(03)00030-2. 
145. Yang A, Zhou Z, Dong Y, Jiang B, Wang X, Chen Z, et al. Expression of immune-related genes in embryos and larvae of sea cucumber Apostichopus japonicus. Fish Shellfish Immunol. 2010;29:839-45. https://doi. org/10.1016/j.fsi.2010.07.023.

146. Potter SC, Luciani A, Eddy SR, Park Y, Lopez R, Finn RD. HMMER web server: 2018 update. Nucleic Acids Res. 2018;46:W200-4. https://doi. org/10.1093/nar/gky448.

147. Altschul S. Gapped BLAST and PSI-BLAST: a new generation of protein database search programs. Nucleic Acids Res. 1997;25:3389-402. https://doi.org/10.1093/nar/25.17.3389.

148. Schultz J, Milpetz F, Bork P, Ponting CP. SMART, a simple modular architecture research tool: identification of signaling domains. Proc Natl Acad Sci. 1998;95:5857-64. https://doi.org/10.1073/pnas.95.11.5857.

149. Letunic I, Doerks T, Bork P. SMART: recent updates, new developments and status in 2015. Nucleic Acids Res. 2015;43:D257-60. https://doi.org/ 10.1093/nar/gku949.

150. Katoh K, Standley DM. MAFFT multiple sequence alignment software version 7: improvements in performance and usability. Mol Biol Evol. 2013;30:772-80. https://doi.org/10.1093/molbev/mst010.

151. Capella-Gutierrez S, Silla-Martinez JM, Gabaldon T. trimAl: a tool for automated alignment trimming in large-scale phylogenetic analyses. Bioinformatics. 2009;25:1972-3. https://doi.org/10.1093/bioinformatics/ btp348.

152. Nguyen L-T, Schmidt HA, von Haeseler A, Minh BQ. IQ-TREE: a fast and effective stochastic algorithm for estimating maximum-likelihood phylogenies. Mol Biol Evol. 2015;32:268-74. https://doi.org/10.1093/ molbev/msu300.

153. Miller MA, Pfeiffer W, Schwartz T. Creating the CIPRES Science Gateway for inference of large phylogenetic trees. In: 2010 Gateway Computing Environments Workshop (GCE). IEEE; 2010. p. 1-8. https://doi.org/10. 1109/GCE.2010.5676129
154. Stone M. Comments on model selection criteria of akaike and schwarz author. J Roy Stat Soc. 1979;41:276-8.

155. Offord V, Werling D. LRRfinder2.0: a webserver for the prediction of leucine-rich repeats. Innate Immun. 2013;19:398-402. https://doi.org/ 10.1177/1753425912465661.

156. Bolger AM, Lohse M, Usadel B. Trimmomatic: a flexible trimmer for Illumina sequence data. Bioinformatics. 2014;30:2114-20. https://doi. org/10.1093/bioinformatics/btu170.

157. Langmead B, Salzberg SL. Fast gapped-read alignment with Bowtie 2 . Nat Methods. 2012;9:357-9. https://doi.org/10.1038/nmeth.1923.

158. Robinson MD, Oshlack A. A scaling normalization method for differential expression analysis of RNA-seq data. Genome Biol. 2010;11:1-9. https://doi.org/10.1186/gb-2010-11-3-r25.

159. Vellutini $B C$, Hejnol A. Expression of segment polarity genes in brachiopods supports a non-segmental ancestral role of engrailed for bilaterians. Sci Rep. 2016;6:32387. https://doi.org/10.1038/srep32387.

160. Olson SA. MacVector: An integrated sequence analysis program for the macintosh. In: computer analysis of sequence data. Totowa, $\mathrm{NJ}$ : Humana Press; 1994. p. 195-201. https://doi.org/10.1385/0-89603-2760:195.

161. Gasiorowski L, Hejnol A. Hox gene expression in postmetamorphic juveniles of the brachiopod Terebratalia transversa. EvoDevo. 2019;10:1-19. https://doi.org/10.1186/s13227-018-0114-1.

\section{Publisher's Note}

Springer Nature remains neutral with regard to jurisdictional claims in published maps and institutional affiliations.
Ready to submit your research? Choose BMC and benefit from:

- fast, convenient online submission

- thorough peer review by experienced researchers in your field

- rapid publication on acceptance

- support for research data, including large and complex data types

- gold Open Access which fosters wider collaboration and increased citations

- maximum visibility for your research: over 100M website views per year

At BMC, research is always in progress.

Learn more biomedcentral.com/submissions 